ARTICLE

https://doi.org/10.1038/s42003-019-0698-6 OPEN

\title{
Repression of phagocytosis by human CD33 is not conserved with mouse CD33
}

Abhishek Bhattacherjee, Emily Rodrigues (10) 1, Jaesoo Jung ${ }^{1}$, Matthew Luzentales-Simpson², Jhon R. Enterina (i) ${ }^{2}$, Danny Galleguillos (1) ${ }^{3}$, Chris D. St. Laurent ${ }^{1}$, Maryam Nakhaei-Nejad ${ }^{4}$, Felix F. Fuchsberger ${ }^{5}$, Laura Streith', Qian Wang ${ }^{3}$, Norihito Kawasaki ${ }^{6}$, Shiteng Duan ${ }^{6}$, Arjun Bains ${ }^{1}$, James C. Paulson (1) ${ }^{6}$, Christoph Rademacher (1) ${ }^{5}$, Fabrizio Giuliani ${ }^{4}$, Simonetta Sipione ${ }^{3} \&$ Matthew S. Macauley (iD) ${ }^{1,2 \star}$

CD33 is an immunomodulatory receptor linked to Alzheimer's disease (AD) susceptibility via regulation of phagocytosis in microglia. Divergent features between human CD33 (hCD33) and murine CD33 (mCD33) include a unique transmembrane lysine in mCD33 and cytoplasmic tyrosine in hCD33. The functional consequences of these differences in restraining phagocytosis remains poorly understood. Using a new amCD33 monoclonal antibody, we show that mCD33 is expressed at high levels on neutrophils and low levels on microglia. Notably, cell surface expression of mCD33 is entirely dependent on Dap12 due to an interaction with the transmembrane lysine in mCD33. In RAW264.7 cultured macrophages, BV-2 cultured microglia, primary neonatal and adult microglia, uptake of cargo - including aggregated $A \beta_{1-42}$ - is not altered upon genetic ablation of $m C D 33$. Alternatively, deletion of hCD33 in monocytic cell lines increased cargo uptake. Moreover, transgenic mice expressing hCD33 in the microglial cell lineage showed repressed cargo uptake in primary microglia. Therefore, mCD33 and hCD33 have divergent roles in regulating phagocytosis, highlighting the importance of studying hCD33 in AD susceptibility.

\footnotetext{
${ }^{1}$ Department of Chemistry, University of Alberta, Alberta, Canada. ${ }^{2}$ Department of Medical Microbiology and Immunology, University of Alberta, Alberta, Canada. ${ }^{3}$ Department of Pharmacology, University of Alberta, Alberta, Canada. ${ }^{4}$ Department of Medicine, University of Alberta, Alberta, Canada.

${ }^{5}$ Department of Biomolecular Systems, Max Planck Institute of Colloids and Interfaces, Potsdam, Germany. ${ }^{6}$ Department of Molecular Medicine, The Scripps Research Institute, La Jolla, CA 92037, USA. *email: macauley@ualberta.ca
} 
S ialic acid-binding immunoglobulin-type lectins (Siglecs) are a family of immunomodulatory receptors with many ascribed roles in controlling immune cell function in health and disease ${ }^{1}$. In humans, 14 members of this family are differentially expressed on cells of the hemopoietic lineage, while nine family members exist in mice, reflecting the rapidly evolving nature of Siglecs ${ }^{2}$. Siglecs can be further subdivided into a conserved CD22-related subfamily and a divergent CD33-related subfamily $^{3-5}$. Siglecs can act as either positive or negative regulators of immune cell signaling, which is primarily dictated by two residues. The first of these key residues is one or more tyrosines in the cytoplasmic tail that are contained within an immunoreceptor tyrosine-based inhibitory motif (ITIM). Under the appropriate physiological circumstance, these tyrosines can be phosphorylated by a Src family kinase and recruit a protein tyrosine phosphatase to dampen immune cell signaling. A second mutually exclusive key residue is a positively charged lysine or arginine in the transmembrane region in certain Siglec family members, which serves to pair Siglecs with an aspartic acidcontaining adaptor protein, such as Dap12. These adaptor proteins have immunoreceptor tyrosine-based activatory motifs (ITAMs) ${ }^{6,7}$, suggesting that Siglecs that pair with Dap12 have the potential to be activatory. Indeed, Siglec- $\mathrm{H}^{8}$ and Siglec- $15^{9}$ in mouse, as well as Siglec-14 $10,-15^{11}$, and $-16^{12}$ in human contain this positively charged transmembrane residue and have ascribed activatory roles ${ }^{13}$.

As has been noted in previous reviews, mouse CD33 (mCD33) has a transmembrane lysine residue and lacks a bona fide ITIM ${ }^{2,3}$. Conversely, human CD33 (hCD33) does not contain this transmembrane lysine and does contain a functional ITIM $^{14}$, although the physiological circumstances in which this ITIM is phosphorylated remains unclear. Little is known about the functional impact these key differences have on the function of $\mathrm{mCD} 33$ and hCD33 since the functional role(s) for CD33 (from mouse and man) in regulating immune cells has not been as easy to elucidate as other Siglec family members. Indeed, no significant phenotype was observed in CD33 knockout mice at the cellular or organismal level ${ }^{15}$. More recently, it was shown that mice reconstituted with $\mathrm{hCD} 33^{-/-}$hematopoietic stem cells are healthy and show no significant alterations in immune cell function compared with their hCD $33^{+/+}$counterparts ${ }^{16}$.

A growing body of evidence implicates CD33 in controlling microglial cell function in the brain ${ }^{17}$. Genome-wide association studies revealed that a single nucleotide polymorphism (SNP) within the $C D 33$ gene correlates with Alzheimer's disease (AD) susceptibility ${ }^{18-20}$. The common CD33 risk allele (rs12459419C) contains a cytidine near the start of exon 2, while the less common CD33 protective allele ( $\mathrm{rs} 12459419 \mathrm{~T}$ ) has a thymidine. Individuals with even one copy of the $C D 33$ rare allele are statistically less likely to develop $\mathrm{AD}$, with two copies being more protective ${ }^{21}$. At the amino acid level, the difference between $\mathrm{C}$ and $\mathrm{T}$ results in an alanine to valine alteration, but this position is contained within the signal sequence and, thus, not present in the fully mature protein. This SNP was, however, found to modulate alternative mRNA splicing ${ }^{22,23}$; exon 2 skipping increases substantially in the $C D 33$ protective allele, leading to production of a short isoform previously described as hCD $33 \mathrm{~m}^{24,25}$. Accordingly, hCD33m lacks its N-terminal sialic acid-binding domain compared with the longer isoform known as hCD33M. Using peripheral blood monocytes ${ }^{21,26}$, or monocyte-derived microglia ${ }^{27}$, it was demonstrated that the copy number of the $C D 33$ protective allele correlates with decreased expression of hCD $33 \mathrm{M}$ and an increased ability to phagocytose cargo such as fluorescent dextran particles and amyloid- $\beta$ peptide. It is noteworthy that the hCD33m isoform, lacking its glycan-binding domain, appears to be unique to humans ${ }^{28}$.
Most phagocytic receptors drive Syk-dependent cellular signaling to promote cytoskeletal rearrangement ${ }^{29-31}$. Therefore, it is highly relevant that inhibitory-type Siglecs can efficiently inhibit Syk-driven cellular signaling through recruitment of phosphatases, such as SHP-1 and SHP-2, that directly dephosphorylate Syk and proximal signaling components ${ }^{1}$. One possible mechanism for the correlation between $\mathrm{AD}$ susceptibility and CD33 alleles is that the common $C D 33$ risk allele, which preferentially gives rise to the long isoform (hCD33M), restrains phagocytosis in brain microglia, leading to the slow accumulation of aggregated amyloid- $\beta$ peptides and thereby increasing the probability of neurodegenerative plaque deposition. It is noteworthy that other models can be envisioned whereby increased expression of the short isoform (hCD33m) has a yet undiscovered protective function. Indeed, a recent metagenomics analysis supporting a possible gain-offunction for hCD $33 \mathrm{~m}$ was proposed ${ }^{17}$, and hCD $33 \mathrm{~m}$ was recently reported to inefficiently reach the cell surface ${ }^{32}$. Support for the loss-of-function model comes from studies wherein mCD33-l- mice crossed with the APP/PS1 or 5XFAD mouse model of $A \beta$ plaque accumulation had decreased plaque accumulation compared with their mCD33-expressing counterparts ${ }^{33,34}$. Likewise, cultured microglia from WT and mCD33-I- neonatal mice were reported to have a differential ability to phagocytose fluorescent $\mathrm{A} \beta_{1-42}$, with $\mathrm{mCD} 33^{-/-}$ microglia having a significantly increased phagocytic capacity.

In the context of the clear differences between mCD33 and hCD33 at certain key functional residues, we were interested in how mCD33 would be able to play an inhibitory role. To begin addressing this question, we developed a monoclonal antibody for mCD33 since previous studies relied on polyclonal antibodies $^{15,33}$. We demonstrate, for the first time to our knowledge, that mCD33 expression on the cell surface requires Dap12. Through genetic manipulation of mCD33 and hCD33 expression in cultured cells and mouse microglia, we address the role of these two proteins in restraining phagocytosis and find strong support for hCD33M in restraining phagocytosis, which is not recapitulated by mCD33. Key to these findings is development of a new transgenic mouse model expressing hCD33 in the microglial cell lineage, which will provide an appropriate mouse model to probe the link between hCD33 and plaque accumulation.

\section{Results}

Expression analysis of mCD33 on immune cell subsets. With the growing connection between CD33 and $\mathrm{AD}$, and the utility of mouse models of $\mathrm{AD}$ for studying mechanisms of disease pathogenesis ${ }^{35,36}$, we felt that clarifying the expression levels of mCD33 on immune cell subsets-including primary microgliawould be useful. Previous work analyzing the expression of mCD33 on immune cells relied on polyclonal antibodies ${ }^{15,33}$, therefore, we established a monoclonal antibody toward mCD33 using a similar approach as we described previously for generation of an aSiglec-F monoclonal antibody ${ }^{37}$. A rat IgG1 monoclonal antibody (clone 9A11) was developed for detection of cell surface mCD33 by flow cytometry (Supplementary Fig. 1). Using this antibody, the expression levels of $\mathrm{mCD} 33$ were assessed on immune cells from WT and $\mathrm{mCD} 33^{-1-}$ mice (Fig. 1). In the spleen, we find the highest expression of $\mathrm{mCD} 33$ on neutrophils $\left(\mathrm{CD} 11 b^{+} \mathrm{Ly}^{-6 \mathrm{G}^{+}} \mathrm{Ly}^{-6 \mathrm{C}^{-}} \mathrm{Cx}_{3} \mathrm{Cre1}^{-} \mathrm{F} 4 / 80^{-}\right.$; Fig. 1a). Low expression was found on plasmacytoid dendric cells ( $\mathrm{pDCs}$;

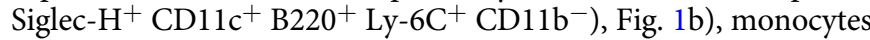
$\left(\mathrm{CD} 11 \mathrm{~b}^{+} \mathrm{Ly}-6 \mathrm{C}^{+} \mathrm{Cx}_{3} \mathrm{Cr}^{+}{ }^{+} \mathrm{F} 4 / 80^{+}\right.$; Fig. 1c), and dendritic cells (DCs; CD19- $\mathrm{CD}^{-} 1 \mathrm{~b}^{\text {low }} \mathrm{CD} 1 \mathrm{c}^{+} \mathrm{MHCII}^{++}$; Fig. 1d). Negligible expression levels were found on natural killer cells $\left(\mathrm{NK} 1.1^{+}\right.$ $\mathrm{CD}^{-} 9^{-} \mathrm{CD}^{-} \mathrm{CD}^{-} 1 \mathrm{~b}^{-} \mathrm{Ly}^{-6 C^{-}}$; Fig. 1e), B cells $\left(\mathrm{CD} 19^{+} \mathrm{B} 220^{+}\right.$; 

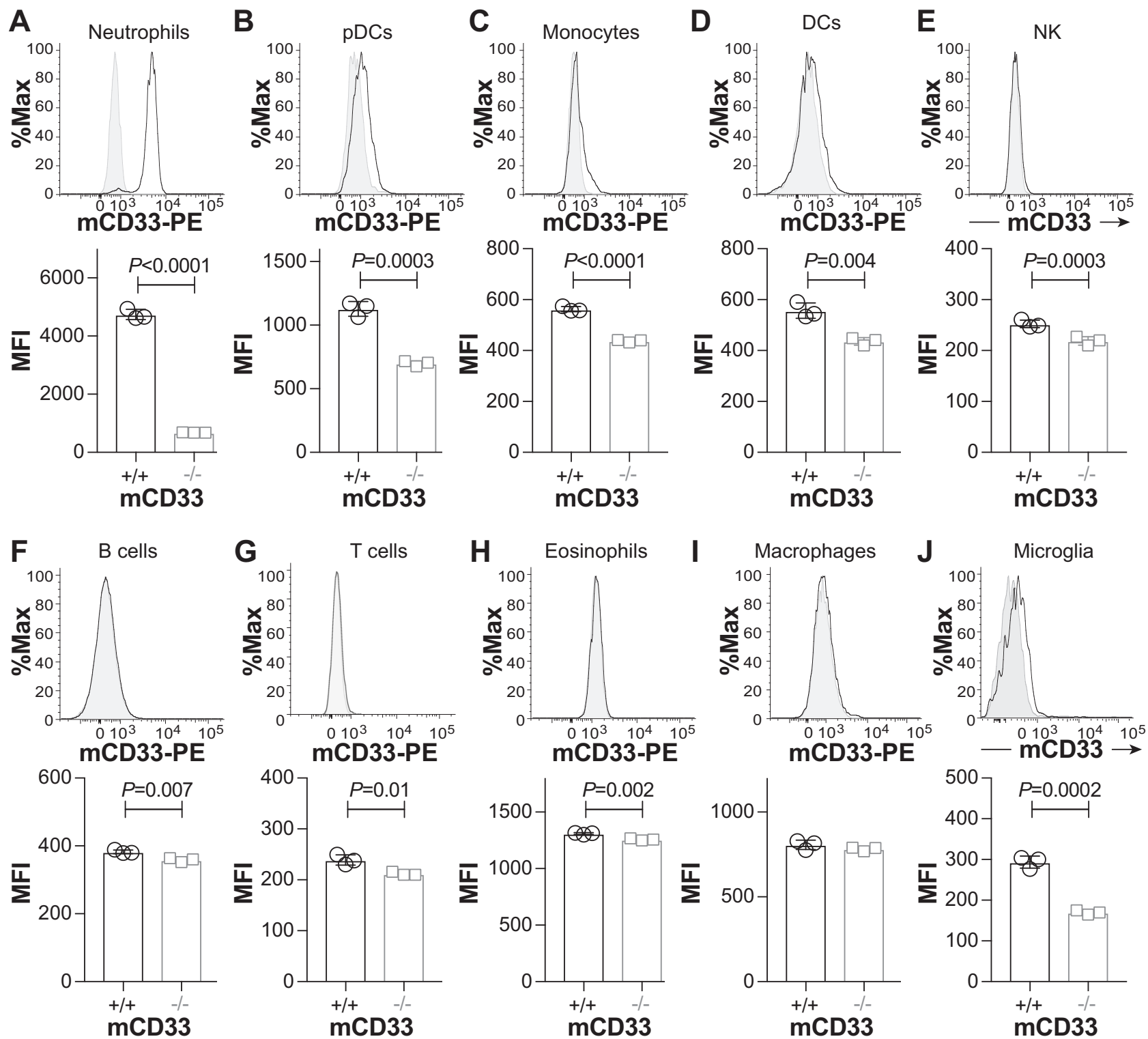

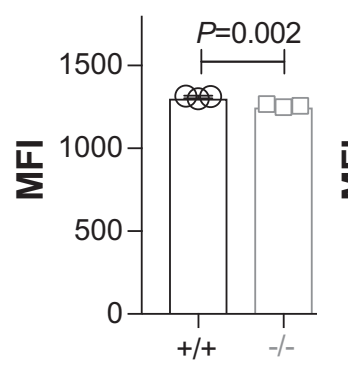

$\mathrm{mCD} 33$

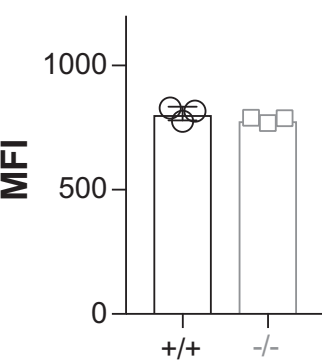

mCD33

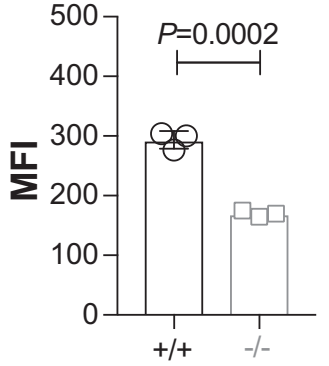

$\mathrm{mCD} 33$
K

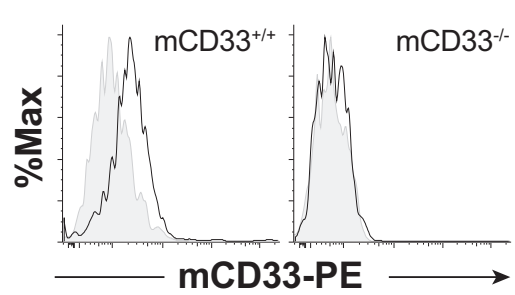

$\mathbf{L}$

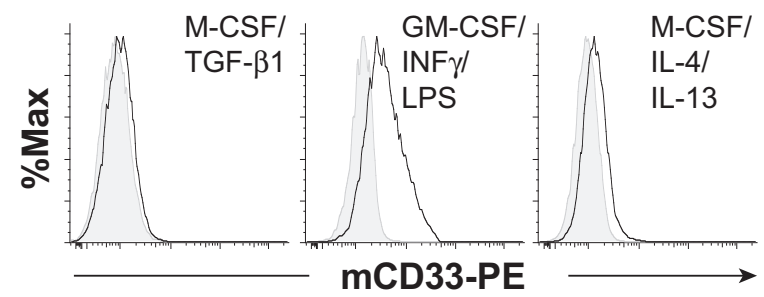

Fig. 1 Expression profile of $m C D 33$ on immune cell subsets. a-i A monoclonal rat lgG1 anti-mouse antibody was used to probe the expression of mCD33 on splenic leukocytes by flow cytometry. For each cell type, a representative histogram (gray: isotype control; black: $\alpha \mathrm{mCD} 33$ ) is shown on the top and a bar graph of the median fluorescence intensity $(\mathrm{MFI})$ for three individual WT $\left(\mathrm{mCD}^{+/+}\right)$and $\mathrm{CD} 33$-deficient $\left(\mathrm{mCD}^{-1-} 3^{-}\right)$mice. j Analysis of mCD33 expression on primary microglia isolated directly from an adult brain via a Percoll gradient from three independent WT and $\mathrm{mCD} 33^{-/-}$mice. $\mathbf{k}$ Levels of $\mathrm{mCD} 33$ expression of microglia derived from the brain of neonatal WT ( $\mathrm{mCD}^{2} 3^{+/+}$; black) and $\mathrm{CD} 33$-deficient $\left(\mathrm{mCD}^{2} 3^{-/-}\right.$; gray) mice. I Levels of mCD33 expression on microglia expanded from the brain of neonatal WT mice cultured with TGF- $\beta 1$ M-CSF, GM-CSF/ INF $\gamma / \mathrm{LPS}$, or M-CSF/IL-4/IL-13. Statistical significance calculated based on an unpaired Student's T-test.

Fig. 1f), $\mathrm{T}$ cells $\left(\mathrm{CD} 3^{+} \mathrm{CD}^{-} 9^{-} \mathrm{CD}^{-11 b^{-}}\right.$; Fig. 1g), eosinophils $\left(\mathrm{CD} 11 \mathrm{~b}^{+} \mathrm{B} 220^{-} \mathrm{CD} 11 \mathrm{c}^{-}\right.$Ly-6Clow; Fig. 1h), and macrophages $\left(\mathrm{F} 4 / 80^{++} \mathrm{Cx}_{3} \mathrm{Cr}^{+} \mathrm{MHCII}^{+} \mathrm{CD}^{+1} \mathrm{~b}^{\text {low }} \mathrm{CD} 11 \mathrm{c}^{\text {low }} \mathrm{Ly}^{-6 \mathrm{C}^{\text {low }}}\right.$ B220-; Fig. 1i). In the brain, low levels of $\mathrm{mCD} 33$ were observed on microglia (CD11b ${ }^{+} \mathrm{Cx}_{3} \mathrm{Cr}^{+}{ }^{+} \mathrm{F} 4 / 80^{+} \mathrm{Ly}_{-} 6 \mathrm{C}^{-} \mathrm{Ly}^{-6 \mathrm{G}^{-}}$; Fig. 1j) isolated directly from adult mice. Low levels of $\mathrm{mCD} 33$ were also found on microglia derived from the brain of neonatal mice (Fig. 1k). Increased mCD33 cell surface levels were observed upon polarization of these neonatal microglia with GM-CSF followed by INF $\gamma$ and LPS, but not with TGF- $\beta 1$ and M-CSF or M-CSF followed by IL-4 and IL-13 (Fig. 11). Transcript levels of mCD33 measured under these same polarization conditions support 
A

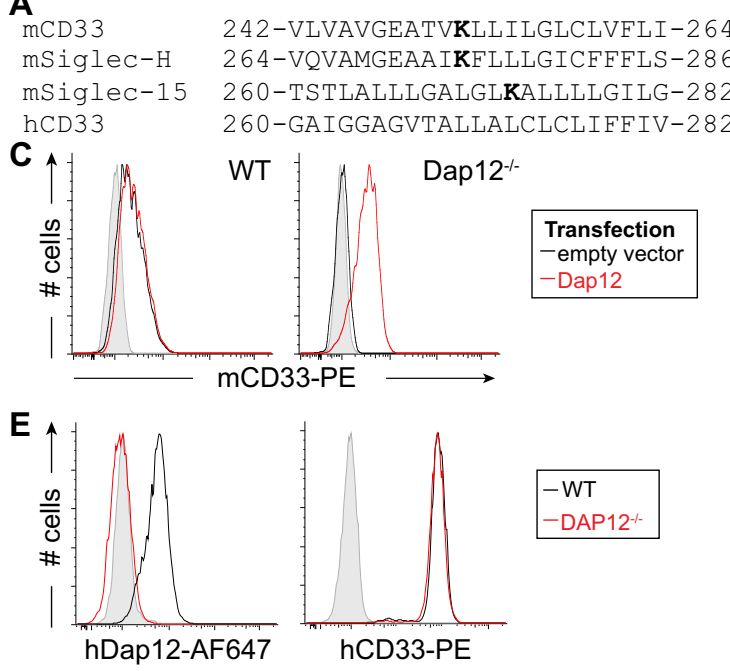

B
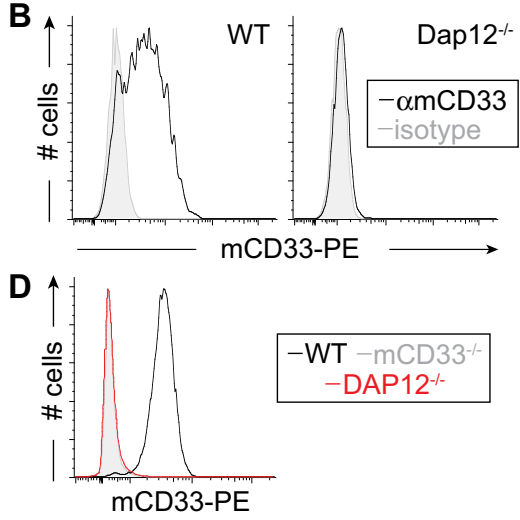

Fig. 2 Dap12-dependent cell surface expression of mCD33. a Sequence alignment of the transmembrane segment of three murine Siglecs bearing a transmembrane lysine residue, shown in bold, along with hCD33. b Flow cytometry analysis of mCD33 expression on WT and CRISPR/Cas9-generated Dap12-/- RAW264.7 cells (gray: isotype control; black: $\alpha$ mCD33). c WT and Dap12-/- RAW264.7 cells were transiently transfected with mDap12 (red) or empty vector (black) and stained with $\alpha \mathrm{mCD} 33$ (black and red) or isotype (gray). d Expression of mCD33 on WT (black), mCD33-/- (gray), and Dap12-/- (red) peripheral blood neutrophils (CD11b+Ly-6G+Ly-6C-). e Expression analysis of Dap12 and hCD33 on WT (black) and Dap12-/- U937 cells (red); isotype is shown in gray and was at the same levels for both cell types.

upregulation of $\mathrm{mCD} 33$ expression under the conditions of GMCSF followed by INF $\gamma$ and LPS (Supplementary Fig. 2).

Dap12-dependent expression of $\mathbf{m C D} 33$. A positively charged residue in the transmembrane region of immune co-receptors often signifies pairing with an adapter protein containing a complementary aspartic acid residue ${ }^{7}$. Such a lysine is found in mCD33 at amino acid 252, which falls within the predicted transmembrane sequence, and is similar to Siglec- $\mathrm{H}$ and Siglec15 , but is notabably absent in hCD33 (Fig. 2a). Cell surface expression of Siglec-H and Siglec-15 are dependent on Dap12 $2^{8,9}$, therefore, to assess a requirement of Dap12 for mCD33 expression, we used CRISPR/Cas9 to delete Dap12 from the RAW264.7 murine macrophage cell line. We find that expression of mCD33 cells is completely lost upon deletion of Dap12 (Fig. 2b). Transient transfection of Dap12 in Dap12 ${ }^{-1-}$ cells restored mCD33 cell surface levels, demonstrating that loss of mCD33 on the cell surface upon deletion of Dap12 was not due to an off-target effect of CRISPR/Cas9 (Fig. 2c). We also assessed mCD33 expression on peripheral blood neutrophils from Dap12-1- mice, which recapitulated the findings that $\mathrm{mCD} 33$ cannot be detected on the cell surface in the absence of Dap12 (Fig. 2d). Contrasting with these results in mouse cells, deletion of Dap12 from human U937 monocytic cells had no effect on the expression levels of hCD33 (Fig. 2e). These findings support $\mathrm{mCD} 33$ as a Dap12-paired receptor, which is a feature not shared with hCD33.

mCD33 does not regulate cargo uptake in cultured cells. To investigate a role for $\mathrm{mCD} 33$ in regulating cargo uptake, we used CRISPR/Cas9 to generate mCD33-deficient RAW264.7 (Fig. 3a) and BV-2 cells (Fig. 3b). To minimize effects that could stem from clonal variability in functional studies, we isolated nine $\mathrm{mCD} 33^{-1-}$ clones and six mCD33 ${ }^{+/+}$clones of RAW264.7 cells, as well as six $\mathrm{mCD}_{3} 3^{-1-}$ and $\mathrm{mCD} 33^{+/+}$of BV-2 cell clones. In the RAW264.7 cells, uptake of four different types of fluorescent cargo was monitored by flow cytometry, including TRITC-dextran (Fig. 3c), blue fluorophore-labeled polystyrene beads (Fig. 3d), pHrodomyelin (Fig. 3e), and HyLight555 aggregated $A \beta_{1-42}$ (Fig. 3f). Loss of mCD33 did not impair the ability of RAW264.7 to take up any of the four cargo. To ensure that we were monitoring internalization in these studies, we performed a time courses of uptake of pHrodo-myelin at 4 and $37^{\circ} \mathrm{C}$, which revealed time-dependent increases at $37^{\circ} \mathrm{C}$ with no conditions where significant differences are observed between $\mathrm{mCD} 33^{+/+}$and $\mathrm{mCD} 33^{-/-}$cells (Supplementary Fig. 3). We also used another readout of cellular uptake to corroborate these findings by visualizing cargo cellular uptake of the polystyrene beads by microscopy. By masking the cell boundary with a cell-penetrating fluorophore, the $\%$ of cells with at least one bead inside the cell was visualized and quantified (Fig. 3g). Using this approach, no difference in \% phagocytosis was observed between six mCD33 ${ }^{+/+}$and six mCD33-l- $\mathrm{RAW} 264.7$ clones in an individual experiment (Fig. 3h) or over five independent experiments (Fig. 3i). In BV-2 cells, uptake of polystyrene beads (Fig. 3j) and aggregated $A \beta_{1-42}$ (Fig. 3k) also showed no mCD33-dependent effect in flow cytometry-based uptake assays, with Cytochalasin-D blocking a significant amount of the uptake.

mCD33 does not regulate cargo uptake in mouse microglia. To compare phagocytosis from $\mathrm{mCD}^{+/+}$and $\mathrm{mCD}^{+/-}$ microglia isolated directly from adult mice, a competitive phagocytic assay was developed since, on average, only $20-30 \mathrm{~K}$ microglia can be isolated from a single mouse brain. Since mCD33 expression levels were insufficient to distinguish the $\mathrm{mCD} 33^{+/+}$and $\mathrm{mCD} 33^{-/-}$microglia, $\mathrm{mCD} 33^{+/+}$and mCD33-l- microglia were tested separately but in competition with age- and sex-matched mCD33 ${ }^{+1+}$ microglia from CD $45.1^{+}$ mice. In this way, CD45.1 vs CD45.2 staining could be used to differentiate the two types of cells (Fig. 4a). Accordingly, the \% phagocytosis of the CD45.2+ WT or CD33-1- microglia was set as a percentage of the WT CD45.1 ${ }^{+}$microglia and overall revealed no difference in uptake of the four different types of cargo for the mCD33 ${ }^{+/+}$and $\mathrm{mCD} 33^{-/-}$microglia (Fig. $4 \mathrm{~b}-\mathrm{e}$ ). We also carried out parallel phagocytosis assays with microglia expanded from the brain of $\mathrm{mCD} 33^{+/+}$and $\mathrm{mCD}^{-1-}$ neonatal mice. No significant difference between $\mathrm{mCD} 33^{+/+}$and $\mathrm{mCD} 33^{-/-}$microglia was observed with aggregated $\mathrm{A} \beta_{1-42}$ (Supplementary Fig. 4). Since polarization conditions that include GM-CSF/INF $\gamma / \mathrm{LPS}$ led to upregulated expression of $\mathrm{mCD} 33$ (Fig. 21), we also performed 
A

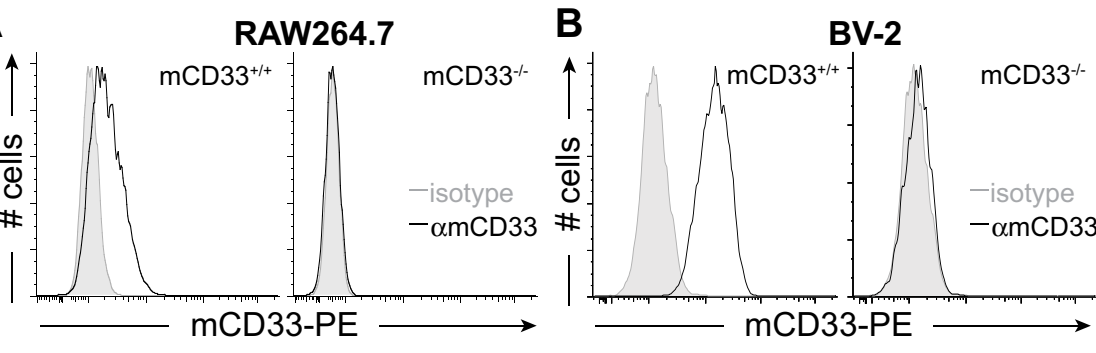

C

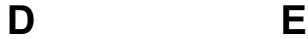

$F$

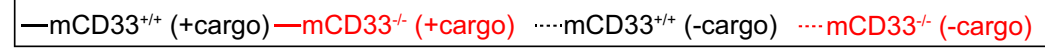
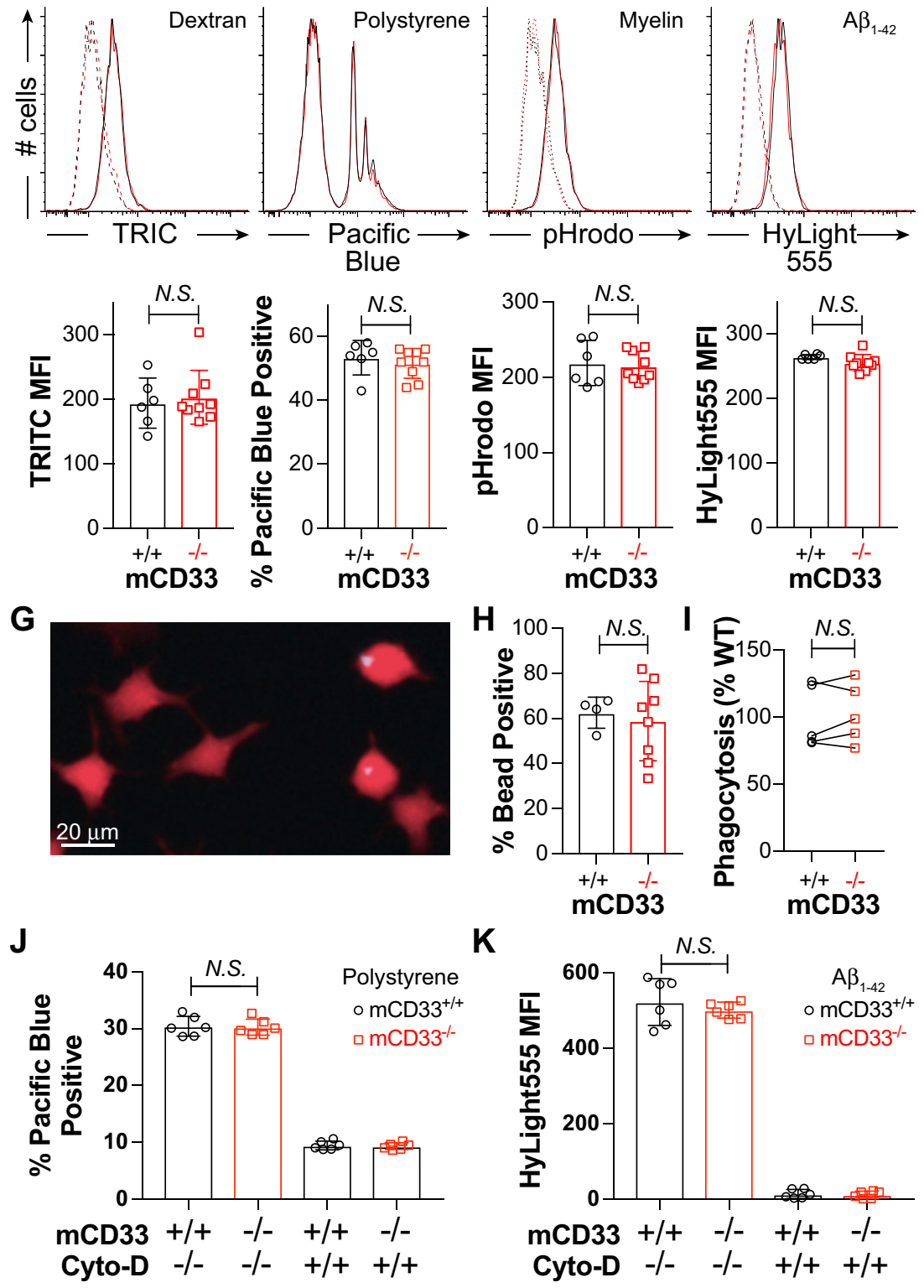

K

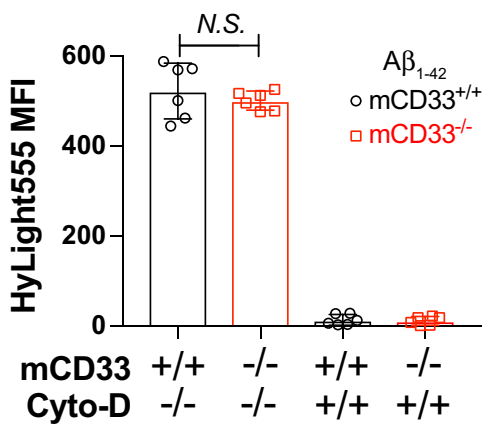

cellular uptake under these differentiated conditions but, again, no mCD33-dependent effects were observed in polystyrene bead or $A \beta_{1-42}$ uptake, both of which was strongly inhibited by Cytochalasin-D (Fig. 4f, g).

Enhanced uptake of cargo due to loss of hCD33 expression. THP-1 and U937, which both highly express hCD33M, were used as human phagocytic cell lines. Using CRISPR/Cas9, variants of

both cell lines lacking hCD33 expression were isolated (Fig. 5a, b). Specifically, we isolated seven different $\mathrm{hCD} 33^{-/-}$and $\mathrm{hCD} 33^{+/+}$ U937 clones, along with three clones of $\mathrm{hCD} 33^{-/-}$and $\mathrm{hCD} 33^{+/+}$ THP-1 cells. All clones were analyzed in flow cytometry-based uptake assays. In U937 cells, we find that uptake of dextran (Fig. 5c), polystyrene beads (Fig. 5d), myelin (Fig. 5e), and aggregated $A \beta_{1-42}$ (Fig. 5f) were significantly and consistently increased in all seven of the clones of U937 cells with disrupted hCD33 expression. Time- and temperature-dependent uptake of 
Fig. 3 Phagocytosis in $\mathrm{mCD} 33^{+/+}$and $\mathrm{mCD} 33^{-/-}$cultured macrophages and microglia. a, b Abrogated expression of mCD33 expression in a RAW264.7, b BV-2 cells by flow cytometry. c-f Flow cytometry-based analysis of $\mathbf{c}$ dextran particles, $\mathbf{d}$ polystyrene beads, e myelin, $\mathbf{f}$, and aggregated A $\beta_{1-42}$ in

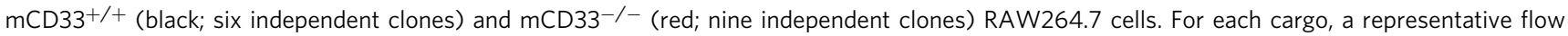
cytometry data and summary plots for each clone, where each data point represents the average of at least three replicates for each clone. Note that for the polystyrene beads, cells incubated without beads are not shown as they overlay directly under the major peak on the left, which represent cells that have not taken up the beads. Statistical significance calculated based on an unpaired Student's T-test. g-i Microscopy-based analysis of polystyrene bead uptake in $\mathrm{mCD} 33^{+/+}(n=4$ independent clones $)$ and $\mathrm{mCD}^{\prime} 3^{-/-}(n=8$ independent clones) RAW264.7 clones. $\mathbf{g}$ Representative image of cells imaged following uptake (red = Calcein, blue = polystyrene bead). $\mathbf{h}$ Results for a single experiment where results for each clone are average for three different wells. i Summary of five independent experiments setting the average levels in the WT clones to 100\%; N.S. represents no statistical significance based on a paired Student's T-test. $\mathbf{j}, \mathbf{k}$ Phagocytosis of polystyrene beads $(\mathbf{j})$ and aggregated $A \beta_{1-42}(\mathbf{k})$ in $\mathrm{mCD} 33^{+/+}$(black; six independent clones) and $\mathrm{mCD}^{-1}{ }^{-/}$(red; six independent clones) BV-2 cells in the absence and presence of $10 \mu \mathrm{M}$ Cytochalasin-D. Statistical significance calculated based on an unpaired Student's T-test.

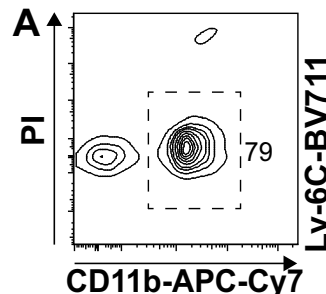

B
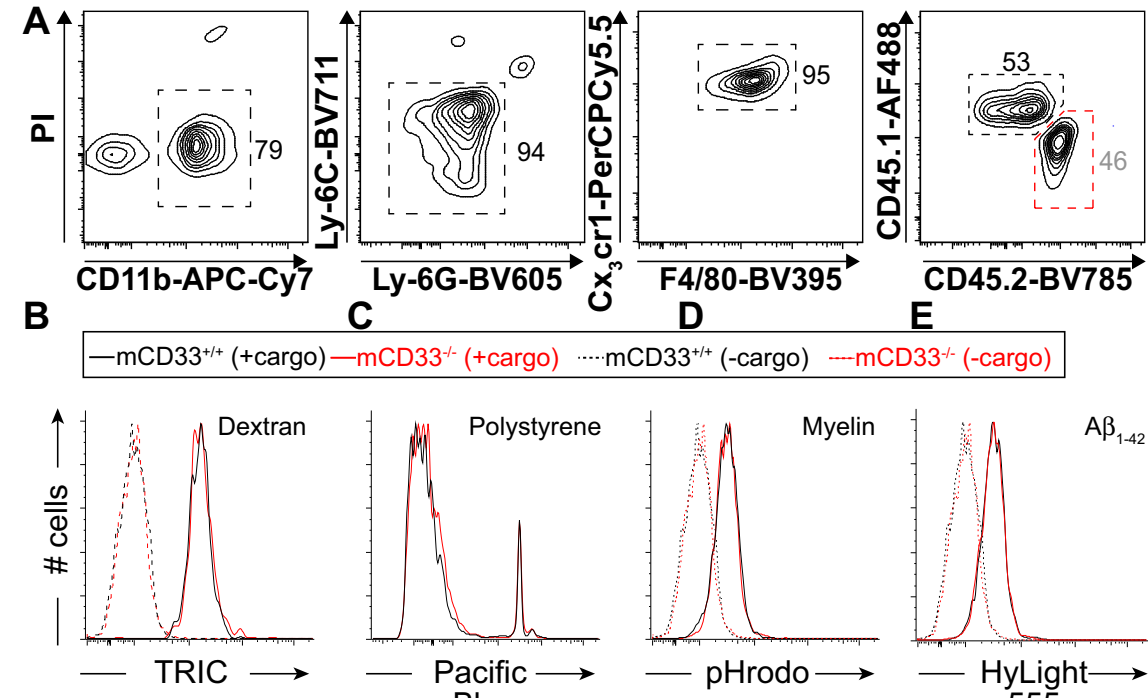

C

D E

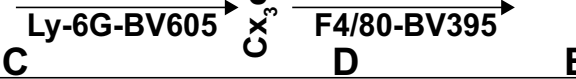

CD45.2-BV785

$3^{-1-}(-$ cargo $)$
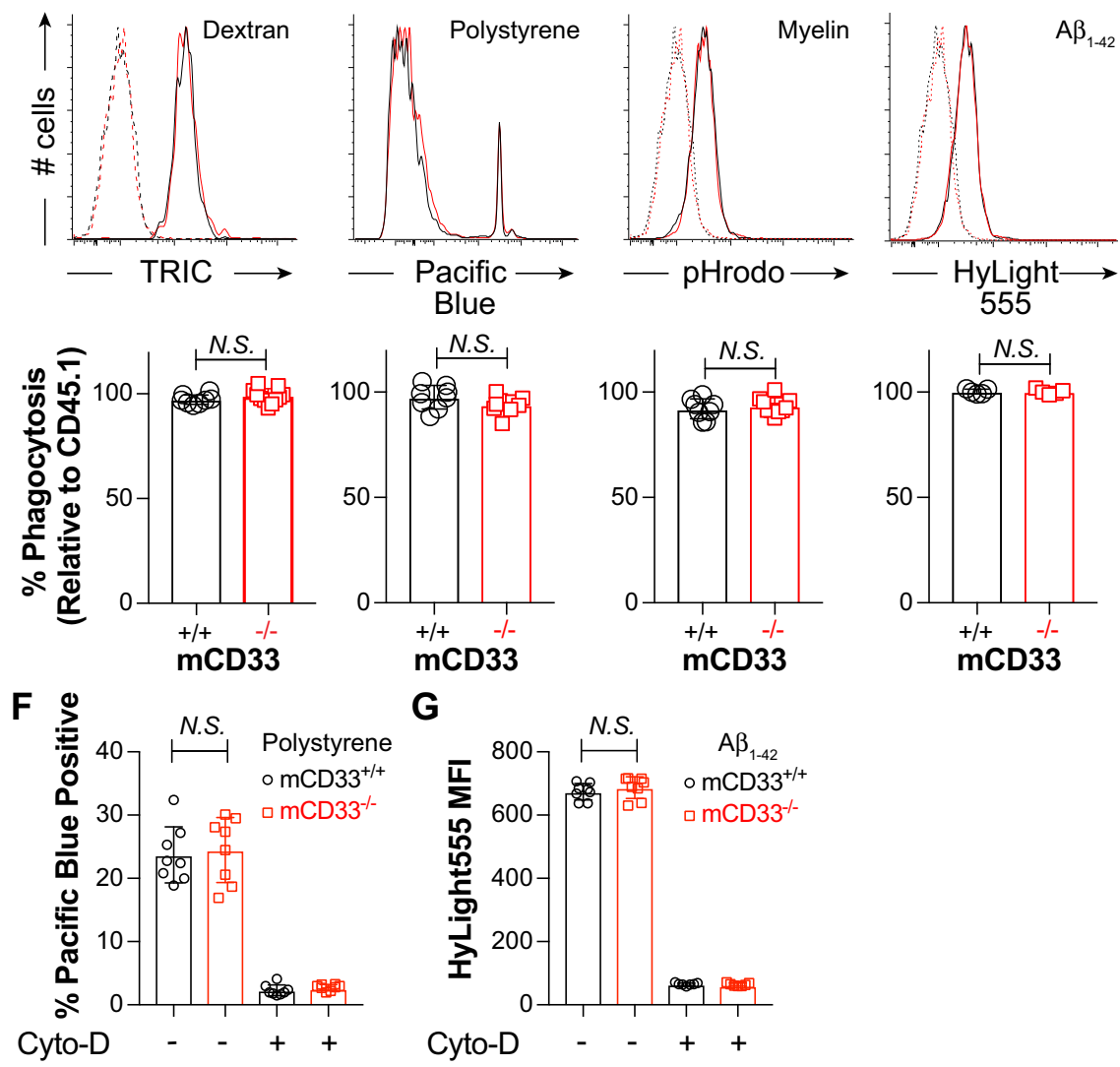

Fig. 4 A competitive phagocytic assay to examine cargo uptake in WT and $m C D 33^{-/-}$primary microglia. a Gating strategy for a flow cytometry-based competitive phagocytosis assay in microglia directly isolated from CD45.2+/+ WT or mCD33-/- mice tested in competition verses microglia from CD45.1+/+ WT mice. b-e Results of the competitive flow cytometry-based uptake of $\mathbf{b}$ dextran particles (11 independent experiments), $\mathbf{c}$ polystyrene beads ( 9 independent experiments), $\mathbf{d}$ myelin ( 9 independent experiments), and $\mathbf{e}$ aggregated $A \beta_{1-42}$ ( 5 independent experiments). Shown are representative flow cytometry histograms for WT $\left(C D 45.1^{+}\right)$versus $\mathrm{mCD} 33^{-/-}\left(\mathrm{CD} 45.2^{+}\right)$and summary plots for each clone for each genotype plotted as a percentage compared with WT CD45.1 ${ }^{+}$cells. $\mathbf{f}, \mathbf{g}$ Flow cytometry-based phagocytosis of polystyrene beads (f) and aggregated A $\beta_{1-42}(\mathbf{g})$ from WT and mCD33-1- microglia expanded from the brain of neonatal mice polarized with GM-CSF/INF $/$ /LPS where each point represents a different mouse $(n=8)$. N.S. represents no statistical significance based on an unpaired Student's T-test. All error bars represent $+/-$ the standard deviation. 

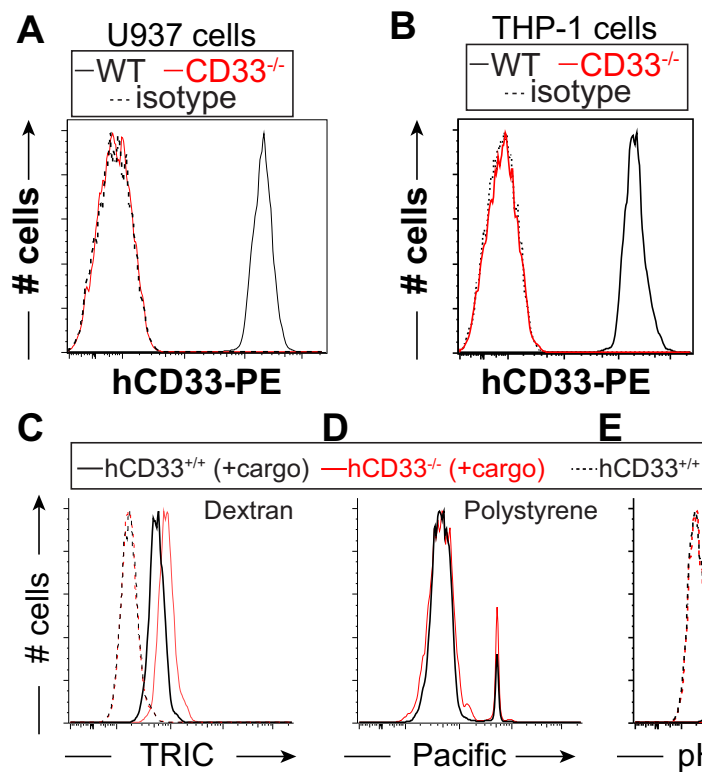

D

E

$\mathbf{F}$

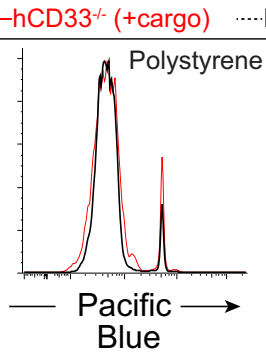

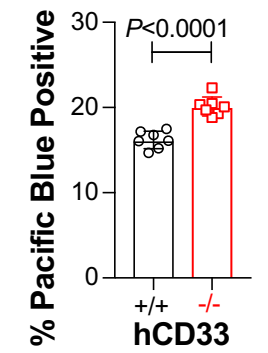

G
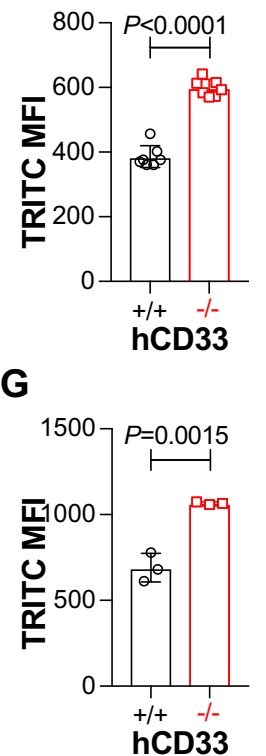

H
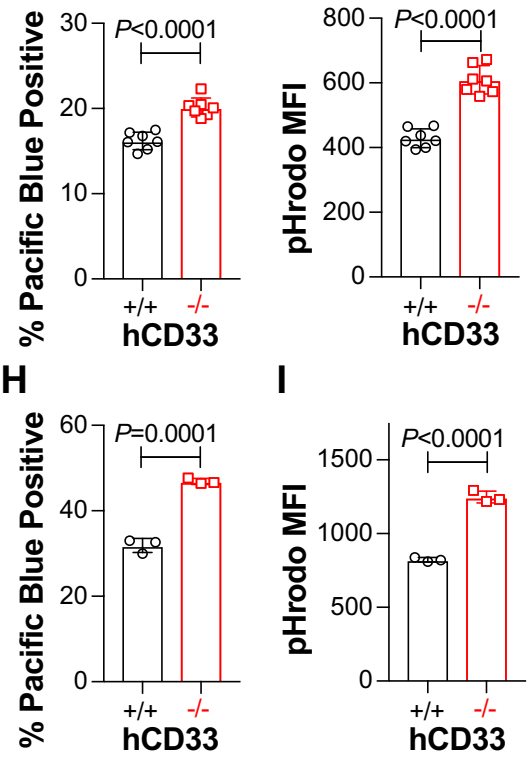

I
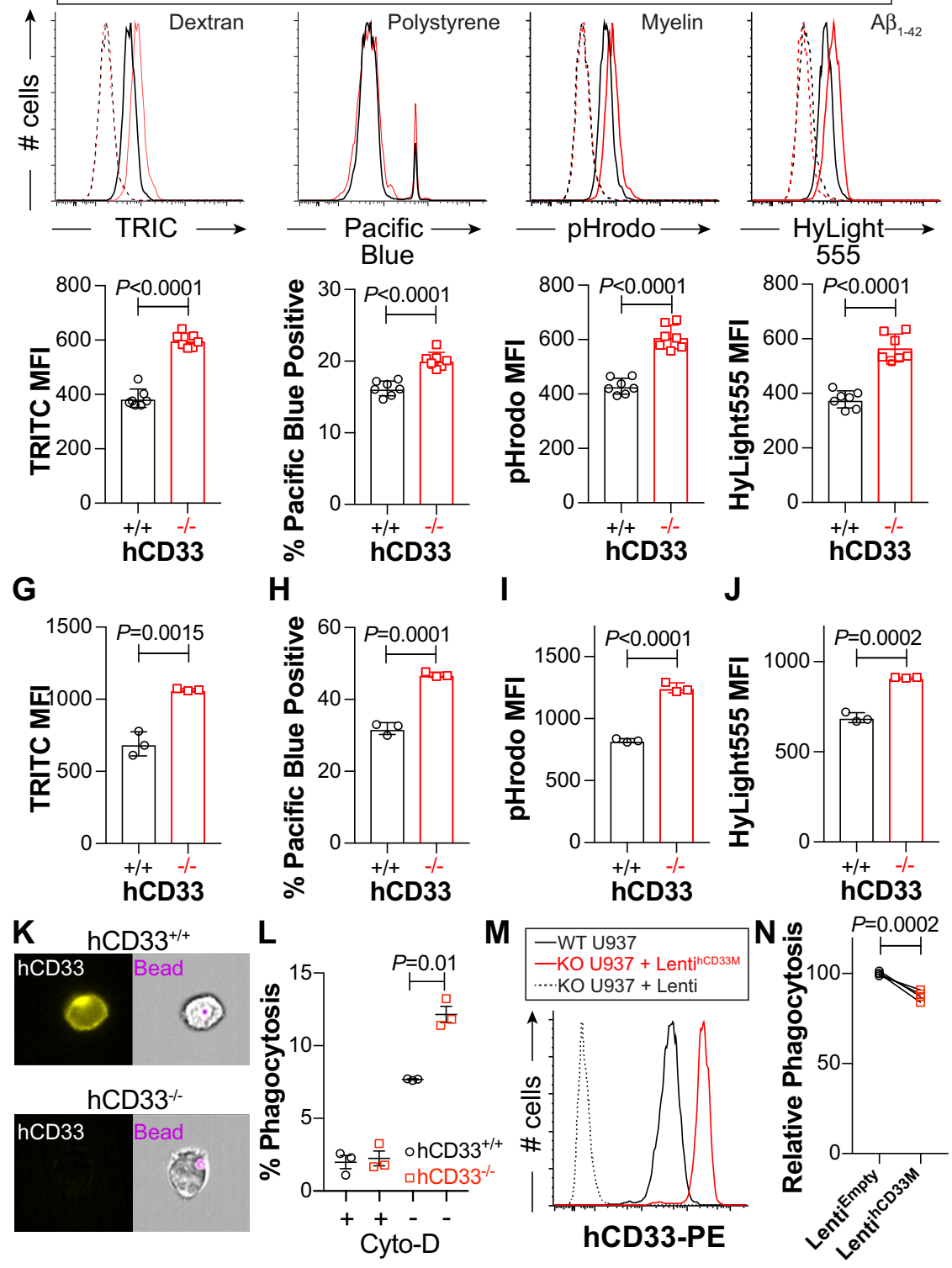

Fig. 5 hCD33 negatively regulates cargo uptake in human monocytic cell lines. Targeted deletion of CD33 by CRISPR-Cas9 in a U937 and b THP-1 cells as demonstrated by flow cytometry staining with $\alpha$ hCD33 (clone WM53). Seven different clones of U937 (c-f) or three different clones of THP-1 ( $\mathbf{g}-\mathbf{j}$ ) were tested in flow cytometry-based uptake of $\mathbf{c}, \mathbf{g}$ dextran particles, $\mathbf{d}, \mathbf{h}$ polystyrene beads, $\mathbf{e}, \mathbf{i}$ myelin, and $\mathbf{f}, \mathbf{j}$ aggregated A $\beta_{1-42}$. For U937 cells (c-f), a representative flow cytometry histogram is shown for each cargo and summary plot of each clone. $\mathbf{k}$ Representative images of phagocytosis of polystyrene beads by $U 937$ cells visualized by imaging flow cytometry. I In three independent experiments, hCD33-/- U937 cells have a higher percentage of cells with internalized polystyrene beads. $\mathbf{m}$ Lentiviral expression of hCD33M in hCD33-/- cells demonstrating that hCD33 expression levels (red) are higher than those of the parent parental U937 cell line expressing endogenous hCD33 (black). Statistical significance based on an unpaired Student's T-test. n Three independent stable cell lines transduced to express empty lentivirus (black) or hCD33M (red) were analysis for phagocytosis with polystyrene beads by flow cytometry. Statistical significance based on a paired Student's T-test. 
pHrodo-myelin by U937 cells showed that $\mathrm{hCD} 33^{-1-}$ cells had increased uptake compared with $\mathrm{hCD} 33^{+/+}$, which was unique to $37^{\circ} \mathrm{C}$ (Supplementary Fig. 5). A similar effect in cargo uptake was observed in hCD33 $3^{-1-}$ THP-1 clones relative to their hCD33 $3^{+/+}$ counterparts (Fig. $5 \mathrm{~g}-\mathrm{j}$ ). To more directly demonstrate phagocytosis of the polystyrene beads, we used imaging flow cytometry to quantify the \% of cells with a fluorescent bead inside of U937 cells (Fig. 5k). The assay was carried out in competition with hCD33-l- and hCD33+/+ U937 cells, with results clearly demonstrating increased phagocytosis in the $\mathrm{hCD} 33^{-1-}$ cells that was ablated by Cytochalasin-D (Fig. 51).

The gRNA used to disrupt the gene encoding CD33 in U937 and THP-1 cells targets the DNA encoding the D2 domain of $\mathrm{hCD} 33$, meaning that expression of both the short (hCD33m) and long (hCD33M) isoforms will be lost. To specifically demonstrate a role for $\mathrm{hCD} 33 \mathrm{M}$ in the repression of cargo uptake, we genetically complemented hCD33-1- U937 cells with hCD33M using lentiviral transduction to restore expression of hCD33M (Fig. $5 \mathrm{~m}$ ). In three independent rounds of transduction, hCD $33^{-1-}$ cells transduced to express hCD $33 \mathrm{M}$ demonstrated a blunted ability to phagocytosis the polystyrene beads compared with cells transduced with control lentivirus (Fig. 5n). The same approach was used to try and overexpress $\mathrm{mCD} 33$ in $\mathrm{hCD} 33^{-1-}$ U937 cells, however, only low levels of $\mathrm{mCD} 33$ on the cell surface could be achieved (Supplementary Fig. 5A). Consistent with the amount of WT mCD33 on the cell surface being limited by its Dap12-dependency, a transduction of lentivirus to express a K252A mutant of $\mathrm{mCD} 33$ achieved high levels of expression (Supplementary Fig. 6A). Importantly, neither WT nor the highly expressed K252A variant of mCD33 suppressed phagocytosis (Supplementary Fig. 6B). These results in monocytic cell lines demonstrate that loss of hCD33 expression results in a $20-50 \%$ increase in cellular uptake of cargo, with genetic complementation of hCD33M restoring phagocytosis.

Dampened cargo uptake in mouse microglia expressing hCD33M. Recently we described a mouse model in which the cDNA encoding the long isoform of hCD33 (hCD33M) was inserted into the Rosa26 locus under control of Cre recombinase ${ }^{38}$. This previous study investigated hCD33 in mast cells, but here we took advantage of $\mathrm{Cx}_{3} \mathrm{Cr} 1^{\text {cre }}$ mice to enable expression of $\mathrm{hCD} 33 \mathrm{M}$ in microglia ${ }^{39}$. Competitive phagocytosis assays were carried out between control $\left(\mathrm{Cx}_{3} \mathrm{Cr} 1^{\mathrm{Cre}+{ }^{-}-} h \mathrm{CD} 33 \mathrm{M}^{--}\right)$and hCD33M transgenic (hCD33M-Tg; $C x_{3} c r 1$ Cre+l- $h C D 33 M^{+/-}$) microglia by taking advantage of the differential expression of bicistronic expression of GFP and hCD33M (Fig. 6a). Using the four aforementioned fluorescent cargo, we observed a consistent $10-30 \%$ decrease in the uptake of the fluorescent cargo in the microglia expressing hCD33M as compared with the WT microglia (Fig. 6b-e). We also assessed microglia expanded from the brain of neonatal mice and found that hCD33M similarly repressed uptake of polystyrene beads and aggregated $A \beta_{1-42}$ (Supplementary Fig. 7). We additionally crossed the hCD33M-Tg mice onto a mCD33 $3^{-1-}$ background and carried out competitive uptake assays between $\mathrm{mCD} 33^{-/-}$ $\left(\mathrm{mCD}_{3} 3^{-1-} \mathrm{Cx} \mathrm{x}_{3} \mathrm{Cr} 1^{\mathrm{Cre}+/-} h \mathrm{CD} 33 \mathrm{M}^{-/-}\right)$and $\mathrm{mCD}^{-1-}$ hCD33M-Tg (mCD33-l- $C x_{3} \mathrm{cr} 1^{\mathrm{Cre}+l-}$ hCD $\left.33 \mathrm{M}^{+/-}\right)$microglia, which revealed that expression of hCD33 still resulted in a significant decrease in uptake of all four cargo (Fig. 6f-i). If $\mathrm{hCD} 33$ and $\mathrm{mCD} 33$ were repressing the same pathways, a larger repressive effect from hCD33 would be anticipated on a mCD $33^{-/-}$background, however, this was not observed. These results provide further support for $\mathrm{hCD} 33 \mathrm{M}$ as a negative regulator of phagocytosis, which is a function not shared by its murine counterpart.

\section{Discussion}

The strong genetic link between variants of $C D 33$ and $A D$ susceptibility suggests that targeting the common risk allele of $C D 33$, which preferentially encodes the longer isoform (hCD33M) containing its glycan-binding domain, could be a treatment strategy in neurodegenerative disease. To better understand if targeting CD33 in $\mathrm{AD}$ is a viable option, a better grasp is needed on the role CD33 plays in modulating the function of microglia. Our findings demonstrate that expression of the long isoform of hCD33 (hCD33M) alone is sufficient to repress phagocytosis in both monocytes and microglia. Our transgenic mice expressing $\mathrm{hCD} 33 \mathrm{M}$ will be a valuable tool for future studies addressing the role of hCD33 in modulating plaque accumulation as well as preclinical testing of therapeutics aimed at targeting hCD33.

Previous work demonstrated that primary mouse microglial cells lacking $m C D 33$ show enhanced phagocytosis towards $A \beta_{1-42}$, correlating with decreased plaque accumulation in APP/PS1 and 5XFAD mice lacking $\mathrm{mCD} 33^{33,34}$. These results suggested a conserved function between murine and human $\mathrm{CD} 33$ as a negative regulator of phagocytosis. We find that in cultured RAW264.7 macrophages, BV-2 cultured microglia, as well as primary mouse microglia from neonatal and adult mice, no difference was observed in phagocytic ability between WT and $\mathrm{mCD} 33^{-1-}$ cells. Moreover, overexpression of $\mathrm{mCD} 33$ in hCD33-l- U937 cells also did not result in impaired phagocytosis. The inability of mCD33 to repress phagocytosis may be related to the absence of an ITIM since overexpression of a K252A mutant of mCD33 achieved a high level of expression in hCD $33^{-1-}$ U937 cells yet still did not repress phagocytosis.

Given that these results are not in line with the earlier findings, we were careful to reach these conclusions by using competitive assays whenever possible, assaying numerous clones of cultured cells to avoid clonal variability, using age- and sex-matched primary mouse microglia, and testing four different types of fluorescent cargo. It is difficult to reconcile why our results differ from those reported previously in terms of a putative role for $\mathrm{mCD} 33$ in repressing phagocytosis but it is worth noting that commercially-available $\mathrm{mCD} 33^{-1-}$ mice are not on a pure C57BL/6 background, as evidenced by the appearance of a gene regulating pigmentation ( $p$ allele) that lies close to the $C d 33$ locus, derived from 129 founder mice ${ }^{15}$. We observed white/gray mice at a significant frequently following initial established of this line from the commercial supplier, but after extensive backcrossing ( $>10$ generations) onto pure C57BL/6J mice, this pigmentation issue was eliminated and these backcrossed mice were used in our experiments. It also remains possible that the decreased plaque deposition in $\mathrm{mCD} 33^{-1-}$ mice is the result of a yet undiscovered role for $\mathrm{mCD} 33$ in regulating microglial cell function.

Through development of the first, to our knowledge, reported monoclonal antibody targeting mCD33, we demonstrate that primary microglia do express low levels of $\mathrm{mCD} 33$, while in the spleen $\mathrm{mCD} 33$ is expressed highest on neutrophils. This latter observation is in line with previous work concluding that granulocytes express the highest levels of $\mathrm{mCD} 33^{15}$, which is also consistent with neutrophils having the highest mCD33 mRNA transcript levels ${ }^{40}$. We also demonstrated, for the first time to our knowledge, that cell surface expression of mCD33 on RAW264.7 cells and primary mouse neutrophils is dependent on Dap12 expression, which strongly suggests pairing of the two proteins. This phenomenon was not observed for hCD33. Thus, in mice CD33, Siglec-H, and Siglec-15 are the Dap12 associated Siglecs ${ }^{8,9}$. A functional role for $\mathrm{mCD} 33$ in regulating immune cells still remains elusive, but demonstrating that $\mathrm{mCD} 33$ pairs with Dap12 opens the door for further research, including a potential activatory role for $\mathrm{mCD} 33$. 
A

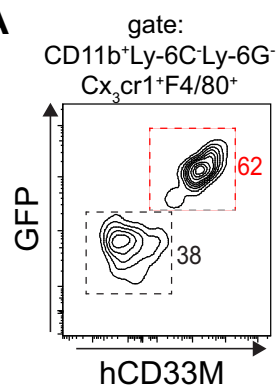

B

C

D E
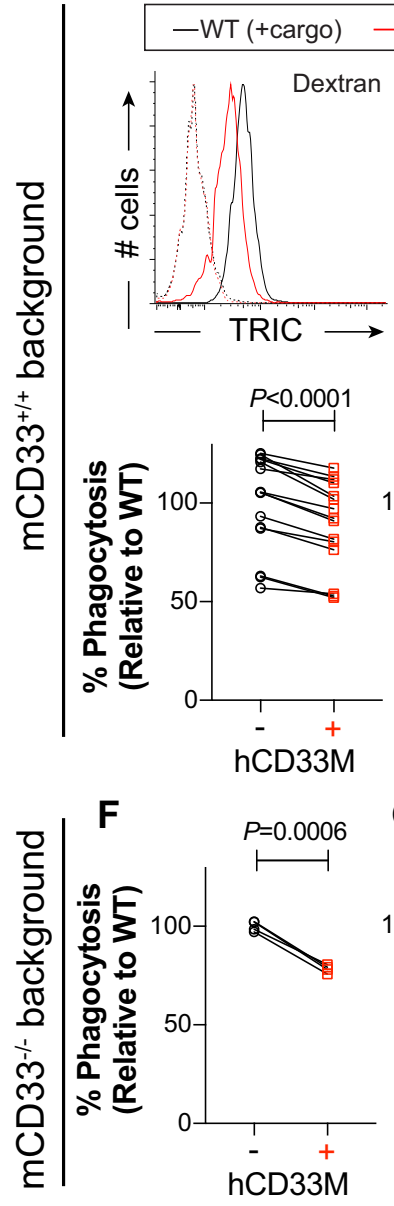

C

\section{E}

hCD33-Tg (+cargo) ….WT (-cargo) …hCD33-Tg(-cargo)
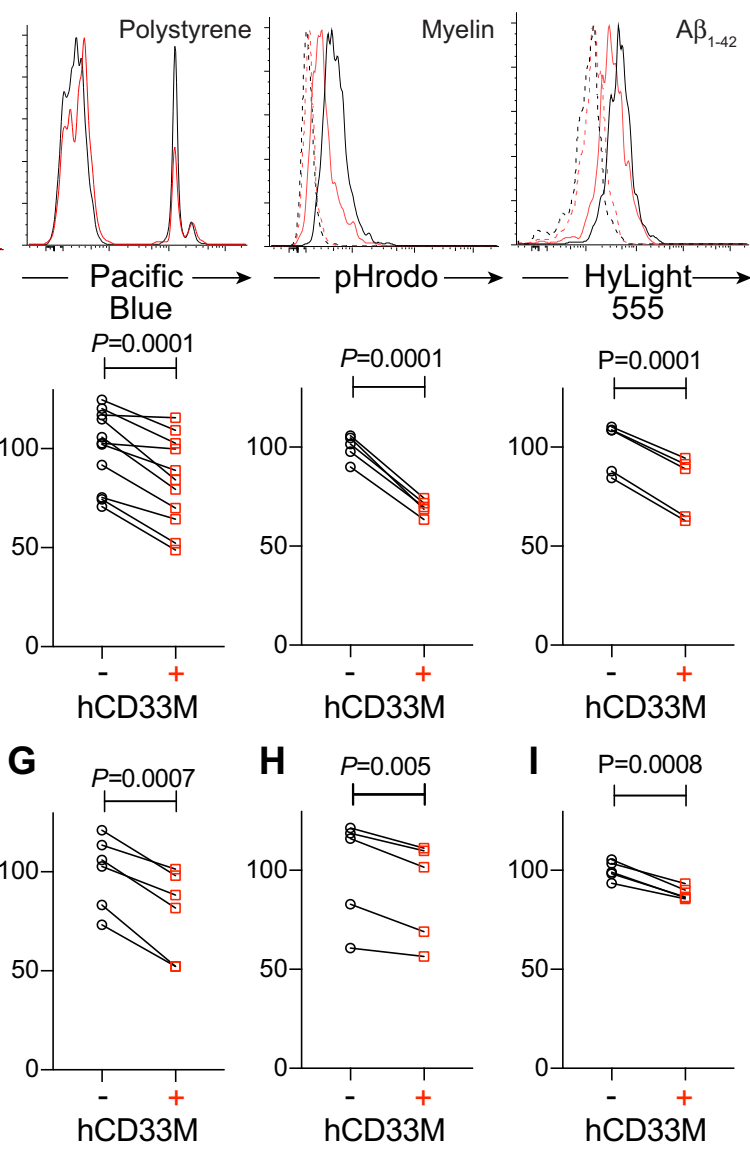

Fig. 6 Transgenic expression of hCD33M in mouse microglial dampens phagocytosis. a Flow cytometry-based competitive phagocytosis gating strategy for WT $\left(\mathrm{GFP}^{-} \mathrm{hCD}^{-} 3^{-}\right)$and $\mathrm{hCD} 33 \mathrm{M}-\mathrm{Tg}\left(\mathrm{GFP}^{+} \mathrm{hCD} 33 \mathrm{M}^{+}\right)$microglia. The competitive phagocytotic assay was carried out with hCD33M-Tg microglia on a $\mathrm{mCD} 33^{+/+}$background $(\mathbf{b}-\mathbf{e})$ or $\mathrm{mCD} 33^{-/-}$background $(\mathbf{f}-\mathbf{i})$ where the non-transgenic $\left(\mathrm{hCD}_{3} \mathrm{M}^{-}\right)$microglia are WT or $\mathrm{mCD} 33^{-/-}$, respectively. Flow cytometry-based uptake of $\mathbf{b}, \mathbf{f}$ dextran particles (14 independent experiments for $\mathrm{mCD} 33^{+/+}$and 4 independent experiments for $\mathrm{mCD} 33^{-/-}$), $\mathbf{c}, \mathbf{g}$ polystyrene beads ( 11 independent experiments and 6 independent experiments for $\mathrm{mCD} 33^{-/}{ }^{-}$), $\mathbf{d}$, $\mathbf{h}$ myelin (5 independent experiments and 5 independent experiments for $\mathrm{mCD} 33^{-/-}$), and $\mathbf{e}$, i aggregated $\mathrm{A} \beta_{1-42}$ (5 independent experiments and 5 independent experiments for $\mathrm{mCD} 33^{-/-}$). For cells on a mCD33 $3^{+/+}$background (b-e), a representative flow cytometry histogram is shown for each cargo and summary plots for each assay, where the average value for the hCD33 non-expressing cells was set to 100\%. Statistical significance based on a paired Student's T-test.

Decreased expression levels of hCD33M in monocyctes bearing the minor protective $C D 33$ allele correlates with enhanced phagocytosis ${ }^{21,26,33}$. However, it cannot be ruled out that this phenotype is influenced by increased expression of the shorter isoform of $\mathrm{CD} 33(\mathrm{hCD} 33 \mathrm{~m})$ generated from exon 2 skipping. We found that loss of hCD33 expression in two monocytic cell lines led to consistent increases in uptake of fluorescent cargo, while transgenic expression of hCD33M in mouse microglia or genetic complementation of hCD33M in hCD33-1- U937 cells gave rise to suppression of cargo uptake. These findings strongly support a role for hCD33M in repressing uptake of cargo within phagocytic cells. Future studies are needed to determine what role hCD33m has in phagocytosis.

In our studies, all four types of fluorescence cargo showed similar hCD33-dependent effects in repressing their uptake, despite having significantly different properties, the most notable being size. The dextran and aggregated $A \beta$ used in our studies have reported radii of 4.5 and $3 \mathrm{~nm}$, respectively ${ }^{41,42}$. Particles of this size are typically thought to enter cells via a mechanism involving clathrin-dependent pinocytosis ${ }^{43}$. On the other hand, 
the myelin and polystyrene beads used in our studies are much larger, with radii $1 \mu \mathrm{m}$ or larger ${ }^{44}$. Particles of this size are taken up by phagocytosis ${ }^{45}$. The ability of hCD33M to regulate uptake of all four cargo may have important implications for its mechanism of action, which clearly warrants further study given that this role could be related to AD susceptibility.

Accumulation of aggregated $A \beta_{1-42}$ drives the formation of amyloid plaques and mouse models to study human genetic factors that modulate this process in vivo have been widely used $^{46}$. Our studies suggest that mCD33 may not be an appropriate surrogate for studying $\mathrm{hCD} 33$. We demonstrate that transgenic expression of hCD33M in the microglial cell lineage inhibits phagocytosis; these hCD33M transgenic mice should provide a valuable model to test the role of $\mathrm{hCD} 33 \mathrm{M}$ in regulating plaque accumulation in vivo, which is currently being tested in ongoing studies in our laboratory. Indeed, establishing a good mouse model to study hCD33 is critical for both better understanding $\mathrm{AD}$ pathology and also testing therapeutics aimed at controlling microglial cell function by targeting hCD33M.

\section{Methods \\ Mice and animal care. All mice were on a C57BL/6J genetic background. WT, $\mathrm{CD} 45.1^{+/+}, \mathrm{Cx}_{3} \mathrm{Cr} 1^{\mathrm{Cre}} 39$, and $\mathrm{mCD} 33^{-/-15}$ mice were obtained from The Jackson Laboratory. Transgenic mice expressing hCD33M in the Rosa26 locus (R26- $h C D 33 M$ ) were described previously ${ }^{38}$. All animals used were maintained in an access-controlled barrier facility under specific-pathogen-free conditions. Studies were performed in accordance with Public Health Service guidelines and approved by the Animal Subjects Committee of the University of Alberta and the IACUC of The Scripps Research Institute.}

Statistics and reproducibility. A Student's $t$-test was used to access statistical significance. When experiments were carried out in competition, a paired Student's $t$-test was used, while an unpaired Student's $t$-test was used in cases where experiments groups were analyzed independently. For experiments using cultured cells to assess phagocytosis, three independent replicates of the experiments were performed with representative results from one of the replicates shown. In some instances, a summary of independent experiments is reported to demonstrate the level of experimental variability and reproducibility of the findings.

Development of a monoclonal antibody targeting mCD33. We anticipated that the transmembrane lysine residue in $\mathrm{mCD} 33$ could be an issue for cell surface expression, we used a strategy previously employed to express Siglec-15 on the surface $\mathrm{CHO}$ cells $\mathrm{s}^{47}$, which involves swapping out the transmembrane and cytoplasmic tail of $\mathrm{mCD} 33$ with that from $\mathrm{mCD} 22$, leaving the extracellular portion of mCD33 (residues 1-240) unchanged. This construct was expressed in $\mathrm{CHO}$ and HEK293 cells as the immunogen and bait for screening supernatant from hybridomas, respectively. Accordingly, $\mathrm{CHO}$ cells expressing this $\mathrm{mCD} 33$ construct were immunized in Rats in the same was as described previously to generate an aSiglecF monoclonal antibody ${ }^{37}$. Isotyping of the antibody took place through incubation of supernatant of the amCD33-expressing hybridoma with $\mathrm{CHO}$ cells expressing the $\mathrm{mCD} 33$ construct, followed by staining with different PE-conjugated secondary antibodies and analysis by flow cytometry. This mCD33 antibody (clone 9A11; originally licensed to eBiosciences, now Thermo Fisher) was used in assessing mCD33 expression on immune cell subsets in its PE-conjugated form.

Cell lines. THP-1, U937, RAW264.7, and BV-2 cells were obtained from ATCC. RAW264.7 and BV-2 cells were cultured in DMEM containing 10\% fetal bovine serum (FBS; Gibco), $100 \mathrm{U} / \mathrm{ml}$ Penicillin, and $100 \mu \mathrm{g} / \mathrm{ml}$ Streptomycin (Gibco). RAW264.7 cells were carefully maintained at a passage number $<30$ since going beyond this leads to variability in phagocytosis ${ }^{48}$. U937 and THP-1 cells were grown in RPMI (Life Technologies) containing 10\% FBS, $100 \mathrm{U} / \mathrm{ml}$ Penicillin and $100 \mu \mathrm{g} / \mathrm{ml}$ Streptomycin.

Flow cytometry and microscopy. All flow cytometry data were collected on a 5laser Fortessa X-20 (BD Bioscience) and analyzed using FlowJo software (BD Biosciences). Images to quantitate phagocytosis in RAW cells and brain sections were acquired on an ImageXpressPico (Molecular Devices) at $\times 20$ and $\times 40$ magnification, respectively, and analysis using CellReporterXpress (Molecular Devices). Cell sorting took place on an Aria III (BD Bioscience). Imaging flow cytometry was carried out on an AMNIS ImageStreamx Mark-II Flow Cytometry system and analyzed using Inspire ${ }^{\mathrm{TM}}$ software.

Isolation of adult mouse microglia. Adult mice were euthanized under $\mathrm{CO}_{2}$. Media used for the primary microglia consisted RPMI with $10 \% \mathrm{FBS}, 100 \mathrm{U} / \mathrm{mL}$
Penicillin and $100 \mu \mathrm{g} / \mathrm{ml}$ Streptomycin. Isolated brain samples were homogenized by a $5 \mathrm{ml}$ syringe plungers in media through $40 \mu \mathrm{m}$ corning filter units under sterile condition. Homogenized samples were centrifuged at $500 \mathrm{rcf}$ for $5 \mathrm{~min}$ and the pellet was treated with $3 \mathrm{ml}$ of red blood cell lysis buffer $\left(150 \mathrm{mM} \mathrm{NH}_{4} \mathrm{Cl}, 9 \mathrm{mM}\right.$ $\mathrm{NaHCO}_{3}$, and $0.1 \mathrm{mM} \mathrm{EDTA}$ ). Following centrifugation at $300 \mathrm{rcf}$ for $5 \mathrm{~min}$, the pellet was dissolved in $3 \mathrm{ml}$ of $30 \%$ Percoll (Percoll PLUS, GE Healthcare) and carefully layered on top of 70\% Percoll and immediately centrifuged (650 rcf for $20 \mathrm{~min}$ ). Immune cells were isolated from the border between the two layers, washed ( $300 \mathrm{rcf}, 5 \mathrm{~min}$ ) and resuspended in media.

Analysis of $\mathbf{m C D} 33$ expression on primary immune cells. $\mathrm{mCD} 33$ expression was accessed in WT and $\mathrm{mCD} 33^{-I}$ mice from within the spleen and brain. For the spleen, it was homogenized in media through a $40 \mu \mathrm{m}$ filter (Corning) under sterile conditions. Samples were centrifuged at $300 \mathrm{rcf}$ for $5 \mathrm{~min}$ and the pellet was treated with $3 \mathrm{ml} \mathrm{RBC}$ lysis buffer $(1 \mathrm{~min})$. Splenocytes or immune cells isolated from the brain (see above) were centrifuged at $300 \mathrm{rcf}$ for $5 \mathrm{~min}$ and treated with $25 \mu \mathrm{l}$ mouse Fc-Block (1:50 dilution) antibody (TruStain fcx ${ }^{\mathrm{TM}}$ anti-mouse clone 93, BioLegend) in flow buffer (HBSS containing 0.1\% BSA and $2 \mathrm{mM} \mathrm{EDTA}$ ). FcBlock antibody treated samples finally stained with $25 \mu \mathrm{l}$ antibody cocktail. For analysis of splenocytes, the following cocktail was used: markers of CD11c (AF488 clone N418, BioLegend), CD19 (BV785, clone 6D5, BioLegend), CD3 (BV650, clone 17A2, BioLegend), B220 (BUV395, clone 6B2, BD Horizon), NK1.1 (BV421, clone PK136, BioLegend), mCD33 (PE, clone 9A11, eBioscience), CX3CR1(AlexaFluor 647, clone SA011F11, BioLegend), Ly-6C (APC/Cy7, clone HK 1.4, BioLegend), Ly-6G (PerCP/Cy5.5, clone 1A8, BioLegend), F4/80 (BV711, clone T452342, BD Horizon), Cd11b (BV510, clone M1/70, BioLegend), MHCII (BV605, clone M5/114,15.2, BioLegend), and Siglec-H (PE-Cy7, clone eBio440C, Invitrogen). For analysis of microglia, the following cocktail was used: F4/80 (BUV395, clone T45-2342, BD Horizon), LY-6G (BV605, clone 1A8, BioLegend), CD11b (APC/Cy7, clone M1/70, BioLegend), $\mathrm{Cx}_{3} \mathrm{crl}$ (PerCP/Cy5.5, clone SA011F11, BioLegend), and Ly-6C (BV711, clone HK 1.4, BioLegend). Cells were stained at $4{ }^{\circ} \mathrm{C}$ for $20 \mathrm{~min}$, washed once, and resuspended in flow buffer containing $1 \mu \mathrm{g} / \mathrm{ml}$ propidium iodide prior to analysis by flow cytometry.

CRISPR/Cas9 gene editing. Custom crRNA (Integrated DNA Technologies; IDT) was designed to target human CD33 (target sequence = GAACACCCCCGATCT TCTCC), mouse CD33 (target sequence = AGGTGTGAACGTCAGCACGG), mouse Dap12 (target sequence = GGGGCTGGAGGGGGCTGGTC), and human Dap12 (target sequence $=$ TGAGACCGAGTCGCCTTATC). Cells were seeded at 500,000 cells per well 1 day prior to transfection in a 6-well tissue culture plate. For one well of a 6-well plate, $6.25 \mu \mathrm{g}$ of Cas9 nuclease (IDT), $1.2 \mu \mathrm{g}$ of ATTO-550 labeled crRNA:tracrRNA (IDT) duplex, $12.5 \mu \mathrm{g}$ Cas9 Plus reagent (IDT), and $7.5 \mu \mathrm{L}$ CRISPRMAX reagent (Thermo Fisher) in $250 \mu \mathrm{L}$ Opti-MEM medium (Gibco). One day after transfection, cells were removed from the plate-in the case of RAW cells-by trypsin digestion, washed, resuspended in $300 \mu$ of cell sorting medium (HBSS, 10\% FBS, 1 mM EDTA), and stored on ice until sorting. Cells were sorted within the University of Alberta Flow Cytometry Core. The top 5\% bright dyes stained with ATTO-550 were sorted into three 96-well plates containing regular culture medium at one or three cells per well for U937 and RAW cell lines, respectively. Cells were grown for $\sim 3$ weeks until a time when colonies were larger enough to be transferred to a 12 -well plate. Once cells were $90 \%$ confluent cells, they were screened by flow cytometry using PE-conjugated antibody for either hCD33 (clone WM53) or mCD33 (clone 9A11). For knockout of mouse Dap12, RAW264.7 clones were initially screen for mCD33 expression and one clone that stained negative for $\mathrm{mCD} 33$ was taken for sequence validation, which involved PCR amplification of a $575 \mathrm{bp}$ fragment surrounding the targeted sequence followed Sanger sequencing that validated insertion/deletion at the correct location. For knockout of human Dap12, U937 cells were screened for Dap12 expression by intracellular flow cytometry staining with PE-labeled anti-Dap12 (clone REA900; Miltenyi).

Transfection of cells with mDap12. The cDNA encoding mDap12 was commercially synthesized (IDT) and obtained in pcDNA3. RAW264.7 cells were seeded in 6-well dishes the day before transfection at $0.5 \times 10^{6}$ cells/well. Cells were transfected with $2 \mu \mathrm{g}$ of DNA using Lipofectamine LTX, according the manufacturer's protocol (Thermo Fisher). The following day, fresh media was added to the transfected cells and 2 days post transfection cells were removed from the plate with $5 \mathrm{mM}$ EDTA and analyzed for mCD33 expression by flow cytometry.

Materials for phagocytosis assays. The follow materials were purchased from commercial suppliers: TRITC-dextran (Tetramethylrhodamine isocyanate-dextran, Sigma, USA), Polystyrene beads (Fluospheres carboxylate-modified $1.0 \mu \mathrm{m}$ blue 350/440, Molecular Probes, Life Technologies), and Amyloid-beta peptide (A $\beta_{1-42}$, HiLyte Fluor 555-labeled, Anaspec Peptide, USA). Aggregation of A $\beta$ was carried out similar to a published protocol ${ }^{49}$. Fluorescently labeled $A \beta_{1-42}(1 \mathrm{mg})$ was dissolved in Hexafluoro-2-propanol (HFIP) at $1 \mathrm{mM}$ to break up existing aggregates. The HFIP was evaporated in a fume hood overnight, dissolved at $400 \mu \mathrm{M}$ in DMSO, and stored in $5 \mu \mathrm{l}$ aliquots at $-80^{\circ} \mathrm{C}$. Frozen aliquots were dissolved in HEPES buffered saline (Sigma) to $20 \mu \mathrm{M}$ and aggregated at $37^{\circ} \mathrm{C}$ for 2 days in the 
dark, aliquoted and stored at $-80^{\circ} \mathrm{C}$. On the day of the experiment, an aliquot was thawed, diluted to $400 \mathrm{nM}$ into cell culture media, and sonicated for $5 \mathrm{~min}$ in a water bath sonicator prior to use in the phagocytosis assay.

Myelin isolation, purification, characterization, and pHrodo labeling. The brain of a 5-month Sprague Dawley rat was isolated, under anesthesia, and immediately stored at $-80^{\circ} \mathrm{C}$ in an airtight container. Brains were weighed and processed for myelin isolation according a previous work ${ }^{50}$. Briefly, Brain was minced and homogenized in ice cold $0.3 \mathrm{M}$ sucrose solution. The homogenate was layered over $0.83 \mathrm{M}$ sucrose solution and ultracentrifuged $\left(75,000 \mathrm{rcf}, 45 \mathrm{~min}, 4^{\circ} \mathrm{C}\right)$. The layers of crude myelin, which was formed at the interface of the two sucrose solutions, were collected and subjected to osmotic shock by resuspension in Tris.Cl buffer. The crude myelin was homogenized and was ultracentrifuged two more times $\left(12,000 \mathrm{rcf}, 15\right.$ and $\left.10 \mathrm{~min}, 4^{\circ} \mathrm{C}\right)$. Myelin was further purified from the crude preparation by another density gradient and subjected to osmotic shock as above. The protein and lipid contents of myelin was characterized by Western blotting and HPLC. MBP (Myelin basic protein) was detected in the sample in high amounts, while there was no evidence of degradation of lipids or proteins. Myelin was labeled with pHrodo (Invitrogen) by resuspension in sodium bicarbonate $100 \mathrm{mM}, \mathrm{pH} 8.5$ at $100 \mathrm{mg} / \mathrm{ml}$ concentration and incubation with $10 \mu \mathrm{M}$ of dye for $1 \mathrm{~h}$ at room temperature. The excess dye was washed out by washing myelin in PBS four times. The labeled myelin was stored in PBS containing $1 \%$ DMSO at $-80^{\circ} \mathrm{C}$.

\section{Microscopy-based phagocytosis assay in RAW264.7 cells. RAW264.7 cell} clones $\left(n=4 \mathrm{mCD}^{3} 3^{+/+} ; n=8 \mathrm{mCD}^{-1-}\right)$ were grown to $\sim 80 \%$ confluency and removed with $5 \mathrm{mM}$ EDTA in PBS. Cell numbers were standardized by cell counting using a hemocytometer. Approximately 25,000 cells were plated, in triplicate, in 96-well flat bottom plate and allowed to adhere and grow in $300 \mu \mathrm{l}$ of media for $24 \mathrm{~h}$. The following day, media was gently aspirated and $200 \mu \mathrm{l}$ of media containing $5 \mu \mathrm{g} / \mathrm{ml}$ Calcein AM (Thermo Fisher) and carboxylate fluorosphere beads (1:625-1:2500 dilution) were added. Plates were incubated at $37^{\circ} \mathrm{C}$ incubator for $30 \mathrm{~min}$, washed with media three times, followed by image capture. To analyze the data, a cell mask was created for Calcein and software (Molecular Devices) was used to calculate cells that were either positive or negative the presence of carboxylate fluorospheres. Between 2000 and 10,000 cells were analyzed per well. The mean of the triplicates for each clone was taken and plotted as an individual point. Data were normalized according the mean of the WT clones for each experiment.

Flow cytometry phagocytosis assays in cell lines. THP-1 and U937 cells were grown to a density of $\sim 1 \times 10^{6} \mathrm{cells} / \mathrm{mL}$ in a T75 flask prior to the assay, harvested, centrifuged, resuspended in media, and 100,000 cells were added to a 96-well Ubottom plates in $100 \mu$ l of media. For RAW264.7 and BV-2 cells, cells were grown to $80 \%$ confluence, removed from the plate with $5 \mathrm{mM}$ EDTA in PBS, and plated in the same way as the THP-1 and U937 cells. To initiate the assay, $100 \mu \mathrm{l}$ of media containing the fluorescent cargo was added to the cells and incubated for $30 \mathrm{~min}$ at $37^{\circ} \mathrm{C}$. During the incubation step, the following concentration of fluorescent cargos were used: TRITC-dextran, $0.5 \mathrm{mg} / \mathrm{ml}$; polystyrene beads, $1: 340$ dilution from a $2 \%$ stock solution from vendor; pHrodo-myelin $(2 \mathrm{mg} / \mathrm{ml})$, and $\mathrm{A} \beta_{1-42}, 400 \mathrm{nM}$. Following this incubation, cells were washed two times with media, resuspended in flow buffer containing $1 \mu \mathrm{g} / \mathrm{ml}$ propidium iodide, and analyzed immediately by flow cytometry. For the dextran, myelin, and $\mathrm{A} \beta_{1-42}$, the extent of phagocytosis was determined by assessing the median fluorescence intensity (MFI) of the fluorescent signal with a background subtraction (cells without cargo), whereas for the polystyrene beads, the $\%$ of cells taking up at least one bead was used. To inhibit phagocytosis, cells were pre-treated with $10 \mu \mathrm{M}$ Cytochalasin-D for $30 \mathrm{~min}$

\section{Competitive phagocytosis in primary microglial cells. To assess microglial} phagocytosis in the most control manner, microglia were used from age- and sexmatched adult mice in competitive phagocytic assay. To compare mCD33 $3^{+/+}$and mCD $33^{-1-}$ microglia, we could not compare head to head since the levels of $\mathrm{mCD} 33$ expression was not sufficient to differentiate. Thus, $\mathrm{mCD} 33^{+/+}$and $\mathrm{mCD} 33^{-/-}$microglia were separately tested head-to-head with $\mathrm{mCD} 33^{+/+}$from $\mathrm{CD} 45.2^{+}$mice. To compare microglia with and without hCD33 expression, cells could be directly compared head-to-head given that the combination of GFP and hCD33 expression easily enabled differentiation. Accordingly, after isolating microglia (Percoll gradient; see above), the appropriate cells were mixed, platted in a V-bottom 96-well plate with $100 \mu \mathrm{l}$ of media, $100 \mu \mathrm{l}$ of media containing the appropriate fluorescent cargo was added at the same concentration as described above for cultured cells, and cells were incubated for $30 \mathrm{~min}$ at $37^{\circ} \mathrm{C}$. Following a wash, cells were stained with a cocktail of antibodies for $20 \mathrm{~min}$ at $4^{\circ} \mathrm{C}$ that included: CD11b (APC/Cy7, clone M1/70, BioLegend), Ly-6G (BV605, clone 1A8, BioLegend), Ly-6C (BV711, clone HK 1.4, BioLegend), Cx 3 crl (PerCP/Cy5.5, clone SA011F11, BioLegend), and F4/80 (BUV395 clone T45-2342, BD Horizon). For $\mathrm{mCD} 33^{-/-}$versus $\mathrm{mCD} 33^{+/+}$analysis, we additionally used the following antibodies: CD45.1 (AF488, clone A20, BioLegend) and CD45.2 (BV785, clone 104, BioLegend). For analysis of microglia expression hCD33, we additionally used the following antibody: hCD33 (PE, clone WM53, BioLegend). Following one wash, cells were resuspended in flow buffer and analyzed by flow cytometry.
Imaging flow cytometry phagocytosis assay. $\mathrm{hCD}^{2} 3^{+/+}$and $\mathrm{hCD} 33^{-/-} \mathrm{U} 937$ cell lines were cultured in complete cell culture medium for at least $48 \mathrm{~h}$ prior to the assay. Prior to the assay, the equal numbers of both cells were mixed and incubated with the polystyrene beads for $30 \mathrm{~min}$ with or without $10 \mu \mathrm{M}$ Cytochalasin-D at $37^{\circ} \mathrm{C}$. After the incubation step, cells were washed, stained with PE-labeled anti-hCD33 and AF647-labeled CD11b, washed, and resuspended in $50 \mu \mathrm{L}$ flow buffer. At least 3000 cells were analyzed. Cell images were acquired at $\times 60$ magnification. To analyze phagocytosis, acquired data were processed using the internalization wizard on the IDEAS software version 6.2. Bright-field images were used to define a mask for the whole cell wherein an internal mask was defined by eroding the whole cell mask by 4 pixels. Doing so enabled the calculation of an internalization score (IS) where a 0.3 IS was set as a threshold for internalization.

Lentiviral vector production and transduction of U937 cells. All lentiviral vectors were made using the previously described Lentiviral backbone, RP $172^{51}$. Cloning hCD33M, mCD33, or $\mathrm{mCD} 33^{\mathrm{K} 252 \mathrm{~A}}$ into the MCS was done using the restriction sites SphI and PacI. Ligated vectors were transformed into Stable competent E. coli (New England Biolabs) to reduce plasmid instability due to recombination. Individual clones were picked and grown up overnight in $7 \mathrm{ml} \mathrm{LB}$ media containing $100 \mu \mathrm{g} / \mathrm{ml}$ ampicillin. Following mini preps (Qiagen), Sanger sequencing confirmed the DNA sequence was correct. Production of lentiviral particles was achieved using triple transfection of HEK293T cells with the designed transfer vectors (RP172-hCD33, RP172-mCD33, and RP172-mCD33 ${ }^{\mathrm{K} 252 \mathrm{~A}}$ ), packaging vector (RP18) containing the viral genes Gag, Pol, and Rev, and an envelope plasmid (RP19) containing VSV-G. Briefly, 150,000 HEK293T cells were plated in $445 \mu$ DMEM growth media (Gibco) containing 10\% FBS and Pen/Strep, in a 24-well plate on day 0 . On day 1 , a transfection mix was made containing $150 \mathrm{ng}$ RP18 (1 $\mu \mathrm{l}), 150 \mathrm{ng}$ RP19 $(1 \mu \mathrm{l}), 300 \mathrm{ng}$ of transfer vector $(2 \mu \mathrm{l}), 1.8 \mu \mathrm{l}$ TransIT $^{\oplus}$-LT1 Reagent (Mirus Bio), and $60.2 \mu$ Opti-MEM $^{\circledast}$ media (Gibco). The mix was vortexed and allowed to sit undisturbed for $15 \mathrm{~min}$. This transfection mix $(55 \mu \mathrm{l})$ was added to wells containing HEK293T cells. The plate was incubated in a tissue culture incubator at $37^{\circ} \mathrm{C}$ and $5 \% \mathrm{CO}_{2}$. Seventy-two hours post transfection (day 4), the supernatant was harvested, spun down to remove residual cell debris, aliquoted, and stored at $-80^{\circ} \mathrm{C}$. U937 cells $(150,000)$ were plated in triplicate in a 24-well plate in $250 \mu \mathrm{l}$ RPMI growth media (Gibco), containing 10\% FBS and Pen/ Strep, and $8 \mu \mathrm{g}$ Polybrene Transfection Reagent (EMD Millipore). A range of virus $(1,10$, or $100 \mu \mathrm{l})$ was added to each well and incubated for $6-8 \mathrm{~h}$ in a tissue culture incubator. After $8 \mathrm{~h}$, the media in each well was topped up to $500 \mu \mathrm{ll}$. Three days post transduction, cells were harvested and resuspended in flow cytometry buffer (HBSS containing $0.1 \%$ BSA and $2 \mathrm{mM}$ EDTA). The titer of each virus was determined by measuring the $\%$ of mAmetrine ${ }^{+}$cells in each well, in the BV510 channel, by flow cytometry. The dilution factor was multiplied by the starting cell number to calculate a titer, which varied between $1.3 \times 10^{7}$ and $4.9 \times 10^{7} \mathrm{TU} / \mathrm{ml}$ (transduction units). U937 cells $(500,000)$ were plated in a 6-well plate, in $1.3 \mathrm{ml}$ growth media, and $10 \mu \mathrm{g}$ Polybrene. lentivirus was added to each well at a MOI $=1$ (multiplicity of infection), to minimize multiple insertion events in positively transduced cells. Plates were incubated for $24 \mathrm{~h}$ then media was topped up to $5 \mathrm{ml}$. Three days post transduction, cells were wash and resuspended in PBS containing $1 \mathrm{mM}$ EDTA and 1\% FBS. Cells were sorted on an Aria cell sorter (BD Biosciences) and $\mathrm{mAmetrine} \mathrm{e}^{+}$cells were collected. The number of mAmetrine ${ }^{+}$cells in each sample ranged from 0.3 to $1.9 \%$. Sorted cells were plated in 12 -well plates and allowed to grow up. As an added measure to ensure success transduction, $300 \mu \mathrm{g} /$ $\mathrm{ml}$ zeocin was added to the cells for 1 week select for transduced cells. Two weeks after the cell sort, $>99.5 \%$ of cells were mAmetrine ${ }^{+}$

Primary microglia cultures and mRNA analysis. Primary mixed glial cultures from P0.5-P1.5 mice were prepared following a previously described method ${ }^{52}$ Briefly, cerebral cortices were enzymatically and mechanically dissociated and cortical cells were seeded in DMEM/F12 10\% FBS (supplemented with 100 units/ $\mathrm{ml}$ Penicillin, $100 \mu \mathrm{g} / \mathrm{ml}$ Streptomycin, $1 \mathrm{mM}$ Sodium Pyruvate, and $50 \mu \mathrm{M} \beta$ mercaptoethanol) and cultured at $37^{\circ} \mathrm{C}, 5 \% \mathrm{CO}_{2}$. Growth medium was replaced every 4 days. At day 8, medium was supplemented with GM-CSF $10 \mathrm{ng} / \mathrm{ml}$. At day 14, microglia were harvested by incubating in DMEM/F12 10\% FBS $15 \mathrm{mM}$ lidocaine and shaking for $15 \mathrm{~min}$ at $200 \mathrm{rpm}$ and further cultured on poly-L-lysine coated plates in DMEM/F12 (supplemented with $1 \mathrm{mM}$ Sodium Pyruvate and $50 \mu \mathrm{M} \beta$-mercaptoethanol) ${ }^{53}$. Cells were let to rest for $24 \mathrm{~h}$ before been dissociated from the well using StemPro Accutase (ThermoFisher) for $20 \mathrm{~min}$ and collected in HBSS. To examine CD33 under different microglial polarization states, conditions describe previously were used ${ }^{54}$. Specifically, primary microglia were treated during 6 days with TGF- $\beta 150 \mathrm{ng} / \mathrm{ml}$ and M-CSF $10 \mathrm{ng} / \mathrm{ml}$ in DMEM/F12 5\% FBS; 4 days with GM-CSF, followed by 1 hour with INF $\gamma 20 \mathrm{ng} / \mathrm{ml}$ and 2 days with LPS $100 \mathrm{ng} /$ $\mathrm{ml}$; or 4 days with M-CSF $25 \mathrm{ng} / \mathrm{ml}$ followed by 2 days with IL-4 $20 \mathrm{ng} / \mathrm{ml}$ and IL$1320 \mathrm{ng} / \mathrm{ml}$. To assess CD33 expression by flow cytometry, medium was removed, cells incubated with Accutase for $20 \mathrm{~min}$ and collected in HBSS prior to staining with antibodies and flow cytometric analysis. For qPCR analysis of mRNA transcript levels, primary murine microglia, cultured and polarized as described above, were lysed in RLT buffer (QIAGEN). RNA was isolated using RNEasy Micro Kit (QIAGEN) and cDNA was synthetized from $\sim 500 \mu \mathrm{g}$ of RNA using Oligo dT primers and SuperScript II (ThermoFischer). qPCR was carried out using PowerUp SYBR Green Master Mix (Applied Biosystems) in a StepOne Plus instrument 
(Applied Biosystems) and mRNA expression of mRNA was normalized over those of cyclophilin.

Reporting summary. Further information on research design is available in the Nature Research Reporting Summary linked to this article.

\section{Data availability}

The authors declare that all data supporting the findings of this study are available within the paper and its supplementary information files. Please contact the corresponding authors (M.S.M.) for access of raw data, which is stored electronically, and will be made available upon reasonable requests.

Received: 3 June 2019; Accepted: 29 October 2019;

Published online: 03 December 2019

\section{References}

1. Macauley, M. S., Crocker, P. R. \& Paulson, J. C. Siglec-mediated regulation of immune cell function in disease. Nat. Rev. Immunol. 14, 653-666 (2014).

2. Crocker, P. R., Paulson, J. C. \& Varki, A. Siglecs and their roles in the immune system. Nat. Rev. Immunol. 7, 255-266 (2007).

3. Cao, H. \& Crocker, P. R. Evolution of CD33-related siglecs: regulating host immune functions and escaping pathogen exploitation? Immunology 132, 18-26 (2011).

4. Crocker, P. R., McMillan, S. J. \& Richards, H. E. CD33-related siglecs as potential modulators of inflammatory responses. Ann. N. Y Acad. Sci. 1253, 102-111 (2012).

5. Bornhofft, K. F., Goldammer, T., Rebl, A. \& Galuska, S. P. Siglecs: a journey through the evolution of sialic acid-binding immunoglobulin-type lectins. Dev. Comp. Immunol. 86, 219-231 (2018).

6. Turnbull, I. R. \& Colonna, M. Activating and inhibitory functions of DAP12. Nat. Rev. Immunol. 7, 155-161 (2007).

7. Lanier, L. L. DAP10- and DAP12-associated receptors in innate immunity. Immunol. Rev. 227, 150-160 (2009).

8. Blasius, A. L., Cella, M., Maldonado, J., Takai, T. \& Colonna, M. Siglec-H is an IPC-specific receptor that modulates type I IFN secretion through DAP12. Blood 107, 2474-2476 (2006).

9. Kameda, Y. et al. Siglec-15 regulates osteoclast differentiation by modulating RANKL-induced phosphatidylinositol 3-kinase/Akt and Erk pathways in association with signaling Adaptor DAP12. J. Bone Min. Res. 28, 2463-2475 (2013).

10. Angata, T., Hayakawa, T., Yamanaka, M., Varki, A. \& Nakamura, M. Discovery of Siglec-14, a novel sialic acid receptor undergoing concerted evolution with Siglec-5 in primates. Faseb J. 20, 1964-1973 (2006).

11. Angata, T., Tabuchi, Y., Nakamura, K. \& Nakamura, M. Siglec-15: an immune system Siglec conserved throughout vertebrate evolution. Glycobiology 17, 838-846 (2007).

12. Cao, H. et al. SIGLEC16 encodes a DAP12-associated receptor expressed in macrophages that evolved from its inhibitory counterpart SIGLEC11 and has functional and non-functional alleles in humans. Eur. J. Immunol. 38, 2303-2315 (2008).

13. Angata, T., Nycholat, C. M. \& Macauley, M. S. Therapeutic targeting of siglecs using antibody- and glycan-based approaches. Trends Pharm. Sci. 36, 645-660 (2015).

14. Paul, S. P., Taylor, L. S., Stansbury, E. K. \& McVicar, D. W. Myeloid specific human CD33 is an inhibitory receptor with differential ITIM function in recruiting the phosphatases SHP-1 and SHP-2. Blood 96, 483-490 (2000).

15. Brinkman-Vand der Linden, E. C. M. et al. CD33/Siglec-3 binding specificity, expression pattern, and consequences of gene deletion in mice. Mol. Cell Biol. 23, 4199-4206 (2003).

16. Kim, M. Y. et al. Genetic inactivation of CD33 in hematopoietic stem cells to enable CAR T cell immunotherapy for acute myeloid leukemia. Cell 173, 1439-1453 e1419 (2018).

17. Estus, S. et al. Evaluation of CD33 as a genetic risk factor for Alzheimer's disease. Acta Neuropathol. 138, 1-13 (2019).

18. Bertram, L. et al. Genome-wide association analysis reveals putative Alzheimer's disease susceptibility loci in addition to APOE. Am. J. Hum. Genet. 83, 623-632 (2008).

19. Hollingworth, P. et al. Common variants at ABCA7, MS4A6A/MS4A4E, EPHA1, CD33 and CD2AP are associated with Alzheimer's disease. Nat. Genet. 43, 429-435 (2011).

20. Naj, A. C. et al. Common variants at MS4A4/MS4A6E, CD2AP, CD33 and EPHA1 are associated with late-onset Alzheimer's disease. Nat. Genet. 43, 436-441 (2011).
21. Bradshaw, E. M. et al. CD33 Alzheimer's disease locus: altered monocyte function and amyloid biology. Nat. Neurosci. 16, 848-850 (2013).

22. Malik, M. et al. CD33 Alzheimer's risk-altering polymorphism, CD33 expression, and exon 2 splicing. J. Neurosci. 33, 13320-13325 (2013).

23. Raj, T. et al. CD33: increased inclusion of exon 2 implicates the Ig V-set domain in Alzheimer's disease susceptibility. Hum. Mol. Genet. 23, 2729-2736 (2014).

24. Hernandez-Caselles, T. et al. A study of CD33 (SIGLEC-3) antigen expression and function on activated human T and NK cells: two isoforms of CD33 are generated by alternative splicing. J. Leukoc. Biol. 79, 46-58 (2006).

25. Perez-Oliva, A. B. et al. Epitope mapping, expression and post-translational modifications of two isoforms of CD33 (CD33M and CD33m) on lymphoid and myeloid human cells. Glycobiology 21, 757-770 (2011).

26. Chan, G. et al. CD33 modulates TREM2: convergence of Alzheimer loci. Nat Neurosci. 18, 1556-1558 (2015).

27. Ryan, K. J. et al. A human microglia-like cellular model for assessing the effects of neurodegenerative disease gene variants. Sci. Transl. Med. 9, eaai7635 (2017).

28. Schwarz, F. et al. Human-specific derived alleles of CD33 and other genes protect against postreproductive cognitive decline. Proc. Natl Acad. Sci. USA 113, 74-79 (2016).

29. Rosales, C. \& Uribe-Querol, E. Phagocytosis: a fundamental process in immunity. Biomed. Res. Int. 2017, 9042851 (2017).

30. Tohyama, Y. \& Yamamura, H. Protein tyrosine kinase, syk: a key player in phagocytic cells. J. Biochem. 145, 267-273 (2009).

31. Gordon, S. Phagocytosis: an immunobiologic process. Immunity 44, 463-475 (2016).

32. Siddiqui, S. S. et al. The Alzheimer's disease-protective CD33 splice variant mediates adaptive loss of function via diversion to an intracellular pool. J. Biol. Chem. 292, 15312-15320 (2017).

33. Griciuc, A. et al. Alzheimer's disease risk gene CD33 inhibits microglial uptake of amyloid beta. Neuron 78, 631-643 (2013).

34. Griciuc, A. et al. TREM2 acts downstream of CD33 in modulating microglial pathology in Alzheimer's disease. Neuron 103, 820-835 (2019).

35. Radde, R. et al. Abeta42-driven cerebral amyloidosis in transgenic mice reveals early and robust pathology. EMBO Rep. 7, 940-946 (2006).

36. Oakley, $\mathrm{H}$. et al. Intraneuronal beta-amyloid aggregates, neurodegeneration, and neuron loss in transgenic mice with five familial Alzheimer's disease mutations: potential factors in amyloid plaque formation. J. Neurosci. 26, 10129-10140 (2006)

37. Gicheva, N., Macauley, M. S., Arlian, B. M., Paulson, J. C. \& Kawasaki, N. Siglec-F is a novel intestinal M cell marker. Biochem. Biophys. Res. Commun. 479, 1-4 (2016)

38. Duan, S. et al. CD33 recruitment inhibits IgE-mediated anaphylaxis and desensitizes mast cells to allergen. J. Clin. Invest. 129, 1387-1401 (2019).

39. Yona, S. et al. Fate mapping reveals origins and dynamics of monocytes and tissue macrophages under homeostasis. Immunity 38, 79-91 (2013).

40. Jojic, $\mathrm{V}$. et al. Identification of transcriptional regulators in the mouse immune system. Nat. Immunol. 14, 633-643 (2013).

41. Leonard, F. et al. Enhanced performance of macrophage-encapsulated nanoparticle albumin-bound-paclitaxel in hypo-perfused cancer lesions. Nanoscale 8, 12544-12552 (2016).

42. Balducci, C. et al. Synthetic amyloid-beta oligomers impair long-term memory independently of cellular prion protein. Proc. Natl Acad. Sci. USA 107, 2295-2300 (2010).

43. Steinman, R. M., Mellman, I. S., Muller, W. A. \& Cohn, Z. A. Endocytosis and the recycling of plasma membrane. J. Cell Biol. 96, 1-27 (1983).

44. Matthieu, J. M., Quarles, R. H., Brady, R. O. \& Webster Hde, F. Variation of proteins, enzyme markers and gangliosides in myelin subfractions. Biochim Biophys. Acta 329, 305-317 (1973).

45. Richards, D. M. \& Endres, R. G. The mechanism of phagocytosis: two stages of engulfment. Biophys. J. 107, 1542-1553 (2014).

46. Shi, Y. \& Holtzman, D. M. Interplay between innate immunity and Alzheimer disease: APOE and TREM2 in the spotlight. Nat. Rev. Immunol. 18, 759-772 (2018).

47. Briard, J. G., Jiang, H., Moremen, K. W., Macauley, M. S. \& Wu, P. Cell-based glycan arrays for probing glycan-glycan binding protein interactions. Nat. Commun. 9, 880 (2018)

48. Taciak, B. et al. Evaluation of phenotypic and functional stability of RAW 264.7 cell line through serial passages. PLoS One 13, e0198943 (2018).

49. Pan, X. D. et al. Microglial phagocytosis induced by fibrillar beta-amyloid is attenuated by oligomeric beta-amyloid: implications for Alzheimer's disease. Mol. Neurodegener. 6, 45 (2011).

50. Larocca, J. N. \& Norton, W. T. Isolation of myelin. Curr. Protoc. Cell Biol. 33, 3-25 (2006).

51. van de Weijer, M. L. et al. A high-coverage shRNA screen identifies TMEM129 as an E3 ligase involved in ER-associated protein degradation. Nat. Commun. 5, 3832 (2014).

52. Saura, J., Tusell, J. M. \& Serratosa, J. High-yield isolation of murine microglia by mild trypsinization. Glia 44, 183-189 (2003). 
53. Rabinovitch, M. \& DeStefano, M. J. Use of the local anesthetic lidocaine for cell harvesting and subcultivation. In Vitro 11, 379-381 (1975)

54. Butovsky, O. et al. Identification of a unique TGF-beta-dependent molecular and functional signature in microglia. Nat. Neurosci. 17, 131-143 (2014).

\section{Acknowledgements}

We thank GlycoNet and Eisai for funding through a strategic partnership agreement between Eisai and the University of Alberta. We also thank CIHR for a project grant to M.S. M., the Canadian Foundation for Innovation (CFI) for an award to MM for equipment used in these studies, and the Canada Research Chairs (CRC) program for a Tier II CRC to MM. J.C.P. acknowledges funding from the National Institutes of Health (NIH; HL107151 and AI132790). We thank Lewis Lanier for access to Dap12-I- mice, Susmita Sarker for help with mouse genotyping, and Basil Hubbard for advice and help with CRISPR/Cas9 work. Flow cytometry was performed at the University of Alberta, Faculty of Medicine and Dentistry Flow Cytometry Facility, which receives financial support from the Faculty of Medicine and Dentistry and CFI awards to contributing investigators.

\section{Author contributions}

A.B. and M.S.M. conceived of the project and wrote the paper. E.R. performed all the genome editing. J.J., M.L.-S., J.E., C.S.-L., A.B., and L.S. carried out supporting experiments. S.D., N.K., and J.P. were involved at early stages of the project in raising the antibody and establishing the hCD33M transgenic mouse. M.N.-N. and F.G. provided key reagents and advise on experiments with myelin. F.F. and C.R. provided assistance with getting the lentivirus transduction of U937 cells working. D.G., Q.W., and S.S. prepared the neonatal primary microglia.

\section{Competing interests}

The authors declare no competing interests.

\section{Additional information}

Supplementary information is available for this paper at https://doi.org/10.1038/s42003 019-0698-6.

Correspondence and requests for materials should be addressed to M.S.M.

Reprints and permission information is available at http://www.nature.com/reprints

Publisher's note Springer Nature remains neutral with regard to jurisdictional claims in published maps and institutional affiliations.

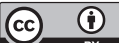

Open Access This article is licensed under a Creative Commons Attribution 4.0 International License, which permits use, sharing, adaptation, distribution and reproduction in any medium or format, as long as you give appropriate credit to the original author(s) and the source, provide a link to the Creative Commons license, and indicate if changes were made. The images or other third party material in this article are included in the article's Creative Commons license, unless indicated otherwise in a credit line to the material. If material is not included in the article's Creative Commons license and your intended use is not permitted by statutory regulation or exceeds the permitted use, you will need to obtain permission directly from the copyright holder. To view a copy of this license, visit http://creativecommons.org/ licenses/by/4.0/.

(C) The Author(s) 2019 